\title{
The Psychology of Cows
}

\author{
Lori Marino $^{1,2^{*}}$ and Kristin Allen ${ }^{3}$
}

\author{
${ }^{1}$ The Someone Project \\ ${ }^{2}$ The Kimmela Center for Animal Advocacy \\ ${ }^{3}$ Florida State University, Tallahassee, FL, USA \\ *Corresponding author (Email: marinolori@ outlook.com)
}

Citation - Marino, L., \& Allen, K. (2017). The psychology of cows. Animal Behavior and Cognition, 4(4), 474-498. https://dx.doi.org/10.26451/abc.04.04.06.2017

\begin{abstract}
Domestic cows (Bos taurus) are consumed worldwide as beef and veal, kept as dairy product producers, employed as draft animals in labor, and are used for a long list of other products, including leather and manure. But despite global reliance on cows for thousands of years, most people's perception of them is as plodding herd animals with little individual personality and very simple social relationships or preferences. Yet, a review of the scientific literature on cow behavior points to more complex cognitive, emotional and social characteristics. Moreover, when cow behavior is addressed, it is almost entirely done within the framework of and applied to their use as food commodities. Therefore, there is relatively little attention to the study of cow intelligence, personality and sociality at a basic comparative level. In this review, we examine the current state of scientific knowledge about cows within an objective comparative framework, describing their cognitive, emotional, and social characteristics. Our aim is to provide a more veridical and objective current summary of cow psychology on its own terms and in ways which will facilitate better-informed comparisons with other animals. Moreover, an understanding of the capabilities and characteristics of domestic cows will, it is hoped, advance our understanding of who they are as individuals.
\end{abstract}

Keywords - Cow, Bos taurus, Cattle, Cognition, Intelligence, Emotions, Personality, Social

Cows (often referred to as cattle) are the most common type of large domesticated ungulates (although there are wild varieties as well). They are a member of the subfamily Bovinae, are the most widespread species of the genus Bos, and are most commonly classified collectively as Bos taurus. Cows are used in a broad range of ways globally. They are raised for meat (beef and veal), for milk and other dairy products, and as draft animals (oxen or bullocks that pull carts, plows and other implements). Other products deriving from cows include leather for clothing and dung for manure or fuel. Despite, or, perhaps because of, their ubiquity as products for our use, most people have a difficult time relating to cows on their own terms, that is, without the biases created by social and economic utility. Most people do acknowledge that some other animals, including cows, possess the ability to experience pain and very basic emotions. Yet, despite empirical evidence for complex emotional, social, and cognitive functioning, there is still a gap between our understanding and acceptance of complex emotions and intelligence between our pets (namely, dogs and cats) and farmed or "food" animals (Herzog, 2010; Joy, 2009).

Cows raised for food in factory farms experience distressful and unnatural conditions from birth to slaughter (Boris, 2011; D'Silva, 2006). And a large body of work has demonstrated that dairy cows and their calves can experience distress during the conventional farming practice of separation from each other (for review, see Enriquez, Hotzel, \& Ungerfeld, 2011; see also Johnsen et al., 2015). Young male calves are reared in isolation pens as veal, horned cattle are subjected to disbudding procedures that produce behavioral and physiological pain responses (Stafford \& Mellor, 2011), and, during transport to slaughter, cows routinely are subjected to hunger, thirst and bodily harm, to name just a few conditions these animals regularly endure (Knowles, Warriss, \& Vogel, 
2014; Weary, Niel, Flower, \& Fraser, 2006). The majority of these procedures are not dictated by concern for cow well-being nor are they necessary for human consumption of cows, but rather they are driven by corporate interests in maximizing profit (Gunderson, 2013). Moreover, cows, like other farmed animals, are being used to create human organs. Given that cows are subjected to so many highly invasive and objectifying practices, the need to understand who they are - on their own terms - is long overdue.

This paper represents a scientific review of what we know about cows in an attempt to place our understanding of them outside of the framework of their use as sources of food, clothing, work, and organ donors. The substantial and growing literature on the psychology of other animals indicating they have rich mental lives continues to have ethically important consequences for how we relate to and treat them. Therefore, understanding the psychology of cows should have a similar impact on our view of them and their wellbeing. The scientific literature on cow psychology and behavior is dominated by applied themes relating their behavioral and cognitive abilities to characteristics mainly relevant to intensive farming (e.g., their ability to grow and reproduce). And because these kinds of applied contexts continue to shape our understanding of cows from both a scientific and public perspective, it is all the more important to objectively assess cows on their own terms by trying to understand their psychology so that we might better align that knowledge with their welfare and interests.

In this paper, we review applied and basic literature on cow cognition, emotionality, personality and social complexity in order to capture the full range of scientific studies available. However, rather than this being simply a comprehensive review of all that is known about cow psychology and behavior, we focus on exploring the behavioral and cognitive capacities demonstrated by cows and on identifying some of the more compelling areas of study for the future. Moreover, whereas there are numerous books about cows and their welfare from a management, husbandry and production perspective (e.g., Grandin, 2015; Moran \& Doyle, 2015; Weaver, 2012) this review focuses on psychological and social characteristics of cows as individuals and on their own terms - a perspective that is routinely neglected. As with any taxonomic group, species-specific factors, such as evolutionary history and sensory abilities, need to be considered in order to more accurately interpret findings on cognition, emotion, sociality, and other characteristics and to make better informed comparisons across taxa. Therefore, what follows is a brief description of the evolution, phylogeny and domestication of cows, as well as what we know of their sensory systems.

\section{Evolution and Domestication}

Cows have been domesticated for human use since the early Neolithic period (as early as around 10,500 BC) from wild aurochs (Bos primigenius). There were two major loci of domestication. These were the Middle East and Europe, giving rise to the taurine lineage, and the Indian subcontinent resulting in the indicine line (McTavish, Decker, Schnabel, Taylor, \& Hillis, 2013). Though European cows are mainly descended from the taurine line, there was gene flow from indicine to taurine lines in the past. Some researchers have suggested that African taurine cattle are derived from a third independent domestication from North African aurochsen. What is clear is that as domesticated cows were moved around, they acquired a substantial dose of genetic admixtures (Decker et al., 2014). Admixed populations were most readily identified when Bos t. indicus and Bos t. taurus animals were hybridized, which occurred in China, Africa, and the Americas. Following their introduction into the Americas in the late 1400s, semiferal herds of cows underwent between 80 and 200 generations of mostly natural selection, as opposed to the human-mediated artificial selection of Old World breeding programs. The complex history of cows makes it abundantly clear that modern cows are a mixture of several different lineages and a range of natural and artificial selective forces (Decker et al., 2014; McTavish et al., 2013).

\section{Sensory-Perceptual Systems}

Cows are diurnal animals and although they rely upon all five sensory modalities, vision is the dominant sense (Adamczyk et al., 2015). They are prey animals and, as such, have eyes located on the sides of their heads, giving them a wide field of view of at least 330 degrees. However, their binocular vision is limited to about $30-$ 50 degrees and they have a blind spot directly behind them. They have good visual acuity, but their accommodation abilities are not as well-developed as those of humans (Adamczyk et al., 2015). Cows are 
dichromatic and are able to distinguish among long wavelength colors (red, orange and yellow) better than shorter wavelengths (blue, green). Cows pay better attention to moving objects than stationary ones and are often "spooked" by sudden movements (Adamczyk et al., 2015).

Hearing ranges are from $23 \mathrm{~Hz}$ to $35 \mathrm{kHz}$, and their hearing is more acute than horses (Heffner \& Heffner, 1983). However, with an average sound acuity localization threshold of 30 degrees, they are less able to localize sounds compared to goats (18 degrees), dogs ( 8 degrees) and humans ( 0.8 degrees). The lack of a keen sound localization ability may make them less certain about the location of a predator and, therefore, more fearful (Adamczyk et al., 2015).

Cows have a well-developed gustatory sense and can distinguish the four primary tastes (sweet, salty, bitter and sour). They possess around 20,000 taste buds. They avoid bitter-tasting foods (potentially toxic) and have a marked preference for sweet (high caloric value) and salty foods (electrolyte balance). Plants have low levels of sodium and cows have developed the capacity of seeking salt by taste and smell. And they have a sensitivity to sour tastes that helps them maintain ruminal $\mathrm{pH}$ balance (Ginane, Baumont, \& Favreau-Peigne, 2011).

Cows are macrosmatic, meaning that they have a keen sense of smell and possess a vomeronasal organ, using the flehmen response (curling back the upper lips to expose the front teeth, inhaling with closed nostrils and holding that position for several seconds) to bring olfactory substances to the organ (Adamczyck et al., 2015). Cows also have a complex complement of odiferous glands, including interdigital, infraorbital, inguinal and sebaceous glands. Olfaction plays a major role in their social life, but the role of olfaction in feeding is not as well known. Generally, cows use their olfactory sense to expand on the information they acquire from other senses, but in the case of social and reproductive behaviors olfaction seems to be a fundamental source of information (Phillips, 2002). Furthermore, there is evidence that cows can detect hormones associated with stress in the urine of conspecifics (Boissy, Terlouw, \& Le Neindre, 1998).

Cows are also very sensitive to touch and have mechanicoreceptors, thermoreceptors, and nociceptors in the skin and muzzle. They use touch to determine the appropriateness of certain food items. They are sensitive to pain but, as they are prey animals, may sometimes suppress familiar signs of pain in order to escape notice by predators (Bomzon, 2011). Nevertheless, a number of reliable signs of pain and distress have been identified in cows (Weary et al., 2006) including during manipulations typical to the farming industry, such as de-horning (Faulkner \& Weary, 2000). Interestingly, while cows are often fearful of touch by humans they are also calmed by some forms of tactile contact such as scratching behind the ears (Moran, 1993).

\section{Method}

We first conducted searches on the Web of Science Core Collection using terms relevant to intelligence, cognition, and behavior and followed up with online Google-based direct searches through all of the major peerreviewed journals (see Table 1) using similar terms as well as key terms from existing papers (e.g., intelligence, cognition, behavior, learning, memory, sociality, self-awareness, etc.). We also used more specific search terms in Web of Science within these broader categories when necessary. Additionally, we used these terms to search on ScienceDaily for relevant news items and peer-reviewed papers. We also conducted a complete search of the websites of the major authors in these fields for all of their relevant projects. Finally, we searched the reference section of each paper to find additional papers in additional miscellaneous journals (not listed in Table 1) and ensured that the overall search was comprehensive. We included books, book chapters, dissertations and theses, as well as both empirical and review papers (which provided further description and interpretation of the empirical data). Both the basic comparative psychology literature and the applied literature were included. No time restrictions were placed on articles for inclusion, but priority was given to more recent papers when appropriate. The reference section of the present paper shows the full breadth of the sources consulted.

We divide our findings into four broad categories: Learning and Cognition, Emotions, Personality, and Social Complexity. 
Table 1

List of Major Peer-Reviewed Journals Searched

$\begin{array}{cc}\text { Animal Behaviour } & \text { Animal Behavior and Cognition } \\ \text { Animal Cognition } & \text { Animal Welfare } \\ \text { Applied Animal Behavior Science } & \text { Behaviour } \\ \text { Behavioural Brain Research } & \text { Behavioural Processes } \\ \text { Brain, Behavior \& Evolution } & \text { Current Biology } \\ \text { Domestic Animal Endocrinology } & \text { Hormones \& Behavior } \\ \text { International Journal of Comparative Psychology } & \text { Journal of Animal Science } \\ \text { Journal of Comparative Psychology } & \text { Journal of Dairy Science } \\ \text { Journal of Mammalogy } & \text { Nature } \\ \text { Physiology and Behavior } & \text { Public Library of Science (PLoS) Biology } \\ \text { Public Library of Science (PLoS) ONE } & \text { Science }\end{array}$

\section{Learning and Cognition}

Cognition refers to the mechanisms by which an individual acquires, processes, stores and acts upon information, and includes learning, memory and decision-making (Shettleworth, 2010). Intelligence, arguably, refers to the quality of these mechanisms in terms of rapidity, depth, and complexity. And there is always an interplay between "higher-level" cognitive processes and those considered to be more basic (Shettleworth, 2010). The scientific literature directly addressing cognition, learning, and memory in cows is relatively scarce. Much of our current understanding of intelligence in cows has to be inferred from other areas of study, including social complexity and communication in other mammals. However, here we summarize what is currently known from the full range of applied and basic studies designed to investigate cognition in cows.

Relatively few direct studies of learning and memory in cows have been done that are not framed in an applied setting (e.g., training cows to access automatic feeders, determining food preferences). Nevertheless, these studies do provide a window into some basic cognitive processes. Moreover, these studies point to robust and rapid learning abilities. Cows can learn about the location of a feeder after two ten-minute tests daily for five days. In one study, their long-term memory was demonstrated when $77 \%$ of the cows retained the learning after a six-week cessation of testing (Kovalchik \& Kovalchik, 1986). In an early study of auditory conditioning, cows learned to respond appropriately to the sound of an alarm within seven trials (Kiley-Worthingthon \& Savage, 1978). Another study of associative learning showed that cows have the ability to quickly (after just a few sessions) learn an association between a non-aversive audio stimulus and an electric shock at a virtual fence boundary, and they maintained that learning without any other cues (Lee et al., 2009). Baldwin and Start (1978, 1981) showed that calves can learn to push their muzzles into an opening to break a beam of light, which turns the house lights on or off. Salt-deficient calves have shown the ability to learn to press a panel for access to sodium solutions (Sly \& Bell, 1979, 1981).

In a test of how well they can extrapolate the location of a moving target, cows were presented with a task called the Krushinskii test. The subjects follow a slow-moving food trolley, eating as they go. When the trolley moves into a tunnel where it cannot be seen (a form of invisible displacement) the subjects should move to the far end of the tunnel to await the exit of the trolley, showing they can extrapolate future movements from the past trajectory of the trolley. Cows are capable of successfully completing this task, though they were not as consistent as pigs and goats (Albright, Kilgour, \& Whittlestone, 1982).

One of the areas sorely lacking in our understanding of cow cognition is object permanence, which is called to mind in studies like the one above. But whereas the cognitive abilities probed by tests like the Krushinskii test only resemble tests of object permanence, there are no actual published studies of object permanence in cows to date. Object permanence is a vital cognitive skill that underlies a number of other complex 
capacities, such as abstraction, prediction across time and space, and perspective-taking (Liberman \& Trope, 2014). Determining what level of object permanence cows or any other animal achieves is important for interpreting their capacities in a number of areas that appear to rely upon mental representation or the forming of higher-level constructs discussed below (Liberman \& Trope, 2014).

Discrimination of objects, shapes, and non-conspecifics. Many studies of cow behavior probe discrimination abilities, that is, the ability to learn and recognize the difference between two stimuli. Object discrimination learning involves the ability to learn to discriminate stimuli or objects on the basis of various attributes of those stimuli through differential reinforcement contingencies (Kehoe, 2008). Clearly, object discrimination is a necessary foundation for other forms of learning and cognition. Object discrimination makes categorization and concept formation possible; these capacities, in turn, can provide cognitive scaffolding for other complex capacities. All animals possess some ability to learn to discriminate objects, and these capacities range from discriminations of simple concrete stimuli to complex and even abstract concepts.

Many mammals, from rodents to nonhuman primates, are capable of rather complex discriminations (Fagot, 2000; Matsuzawa, 2001; Zentall \& Wasserman, 2006). Dogs are able to classify color photographs of natural stimuli (Range, Aust, Steurer, \& Huber, 2008). And complex object discrimination has been demonstrated in other farmed animals (e.g., pigs, Sus scrofa; Croney, Adams, Washington, \& Stricklin, 2003; Hemsworth, Verge, \& Coleman, 1996; Tanida \& Nagano, 1998). Pigeons (Columbia livia) and other bird species are capable of categorizing and differentiating various stimuli as well (e.g., Huber, Apfalter, Steurer, \& Prossinger, 2005).

Cows can discriminate a wide range of stimuli. In operant conditioning discrimination paradigms cows can discriminate between geometric shapes (Baldwin, 1981), colors (Gilbert \& Arave, 1985), the same shapes differing by size (Rehkämper \& Görlach, 1997), and even stimuli differing by both brightness and size (Schaeffer \& Sikes, 1970). Cows are able to discriminate more complex stimuli than just static geometric stimuli, however. For instance, they are able to discriminate among individual humans on the basis of a number of dimensions. One of those is handling. Calves as well as adult cows show learned fear responses to humans who have previously handled them in a rough manner (Hotzel, Machado Filho, Yunes, \& Silveira, 2005; Munksgaard, de Passillé, Rushen, Thodber, \& Jensen, 1997). Adult cows have the ability to learn to differentiate handlers who wear the same clothes. In one study, cows were taught to press their noses to the right wrist of a handler to obtain a food reward. The experiment consisted of two handlers, one who responded to the subjects by giving food while the other did not. The cows learned to approach the handler conferring a reward more often than the non-rewarding handler (Taylor \& Davis, 1998). This associative learning ability underwrites even more complex capacities in other areas such as conspecific discrimination in social contexts (discussed below).

Discriminating conspecifics. The ability to discriminate among individuals forms the basis for social relationships, hierarchies, and reactions to familiar versus unfamiliar individuals. It underlies the more complex social characteristics of cows described later on in the paper. Individual discrimination is not the same as, but is a prerequisite to, the more complex capacity for true individual recognition, defined as a mental representation of an individual's identifying characteristics. Thus, individual discrimination is a logical beginning for investigating a species' general social recognition abilities. A number of animals can discriminate individuals, including dogs (Molnár, Pongrácz, Faragó, Dóka, \& Miklósi, 2009), elephants (Loxodonta africana; McComb, Moss, Sayialel, \& Baker, 2000) and pigs (de Souza, Jansen, Tempelman, Mendl, \& Zanella, 2006). These kinds of capacities not only underlie the ability to recognize kin from nonkin and stranger from familiar individual, but also allow for finer discriminations of individual identity within one's social network.

There is a substantive literature showing that cows are able to make discriminations among conspecifics under a variety of circumstances. In a Y-maze discrimination paradigm, heifers were able to quickly (in a few trials) learn to discriminate familiar conspecifics and retain that information for at least twelve days (Hagen \& Broom, 2003). Heifers can also learn to recognize individual cows even if, at the beginning of the testing, the individuals differed in familiarity (Coulon, Delatouche, Heyman, \& Baudoin, 2009). Heifers can also discriminate members of their own species from members of other species (dogs, sheep, horses and goats). Rigorous controls for the amount of black and white surface, size of head, and other visual aspects of the stimuli ensured that simpler features that distinguish cows from other species could not be used. This particular task requires a complex capacity for categorization as the subjects were also presented with cows of various breeds and, therefore, various phenotypes. Yet, in just a few sessions, the cows were able to discriminate photographs of 
different kinds of cow faces from faces of other species. These findings show that the cows could categorize the "sameness" of all the other cow faces despite phenotypic variability as a separate group from the faces of other species (Coulon et al., 2007). In a later study, Coulon, Baudoin, Heyman, and Deputte (2011) showed that heifers can discriminate two-dimensional facial images of familiar and unfamiliar cows. They also provided results that suggested cows categorized the stimuli into familiar versus unfamiliar categories very early in the testing process and that the images were treated as mental representations of real individuals. Pictorially naïve heifers chose pictures of a familiar conspecific immediately upon entering the arena. This suggested to the authors that the heifers used previously stored mental images from actual social interactions as representations of real individuals. Control tests were congruent with that interpretation. Additionally, the use of only photographs in the experiment suggests cows have a sophisticated visual discrimination capacity that is independent of chemosensory mechanisms.

Spatial cognition. Spatial cognition (learning and memory) refers to the ability to acquire knowledge of, remember, organize and utilize information about spatial aspects of one's environment, including navigation and learning to discriminate and prioritize the locations of objects. Some forms of spatial learning are dependent upon mental representations in both short and long-term memory and can form the basis of complex cognitive maps of the environment, providing the foundation for many other social and non-social strategic behaviors during such tasks as foraging and traveling. The complex spatial abilities of food-caching birds are well known (Balda \& Kamil, 2002; Shettleworth, 2002) and many other taxa display sophisticated navigational and spatial foraging capacities as well, including rodents (Bird, Roberts, Abroms, Kit, \& Crupi, 2003) and fish (Brown, 2015). Dogs, too, demonstrate complex spatial navigational and search capacities suggesting that they use cognitive maps (see Bensky, Gosling, \& Sinn, 2013, for a review). This also may be true for pigs (see Marino \& Colvin, 2015, for a review). Chimpanzees and other nonhuman primates also possess sophisticated spatial-navigational memory and learning capacities, in some cases, on a par with four-year old humans (e.g., Garber \& Dolins, 2014).

Grazing animals, such as cows and sheep, perform very well in maze tests, indicating they have good spatial memory, which allows them to graze with optimum efficiency. There is a fairly substantive body of evidence for this conclusion. In a Hebb-Williams closed-field test of how cows navigate through mazes using detours, they performed favorably compared with pigs, sheep, goats, and dogs (Kilgour, 1981). Bailey, Rittenhouse, Hart, and Richards (1989) conducted two studies to examine the spatial memory of cows. In the first study, the performance of heifers was evaluated in radial- and parallel-arm mazes at two levels of complexity. In the second study, the time course of spatial memory was examined in steers. The authors found that the subjects in both studies learned the mazes efficiently, had the ability to associate several different locations with food, and retained this knowledge for up to $8 \mathrm{hrs}$. The authors suggested that visual cues were used, but they could not control or account for all of the factors involved in their performance. Moreover, when given the opportunity, cows will often employ systematic search strategies such as non-random walking paths, decreasing distance walked between food sources, and adjusting search patterns depending upon whether food was clumped or dispersed. Both memory and strategy contribute to optimal foraging efficiency (Laca, 1998).

A number of other studies support the conclusion that cows have robust spatial memory abilities. Ksiksi and Laca (2002) found that steers remembered the location of food buckets for at least 48 hours. Some cows are not only capable of learning simple mazes or the location of food in fields but also can learn to traverse a complex maze (defined as one with multiple arms) when they are provided with step-by-step learning opportunities. Once learned, they can retain the memory of the maze configuration for up to 6 weeks (Hirata, Tomita, \& Yamada, 2016). Moreover, they can retain a memory of an association between a visual cue (a plastic tub) and a food reward for at least a year (Hirata \& Takeno, 2014).

Summary of learning and cognition in cows. There is sufficient evidence demonstrating cows have well-developed discrimination and spatial cognitive abilities and are capable of not only complex learning but feats of long-term memory. They are capable of making discriminations among complex stimuli (humans and conspecifics). However, in general, it would be a vast understatement to conclude that more basic research directly probing cow learning and cognitive abilities in a wider range of domains is needed. For instance, further studies of object permanence would be important as a comparative literature with other animals. And other compelling areas, such as numerosity, learning set, and time perception beg to be addressed. 


\section{Emotions}

The concept of emotion is complex and shares "fuzzy boundaries" with other aspects of overall psychology. Emotions comprise behavioral, neurophysiological, cognitive and conscious subjective processes (Mendl \& Paul, 2004; Paul, Harding, \& Mendl, 2005) and can shape attention, decision-making, and memory. Emotions, themselves, are influenced by such factors as situational awareness and sensitivities to the experience of others. Emotions and cognition are often intimately tied together in a complex interplay (e.g., recollection of memories can generate strong emotions and, in turn, modulate one's response to various stimuli; Mendl, Burman, Parker, \& Paul, 2009; Ohl, Arndt, \& van der Staay, 2008; Paul et al., 2005).

The idea that many nonhuman animals experience basic emotions is currently well accepted (if not the idea that other animals possess complex emotions). This is particularly the case in mammals, despite the fact that much of the picture remains to be filled out in terms of details and taxonomic distribution (Bekoff, 2005; Panksepp, 2004). Many studies of emotions in other animals refer instead to "affective state" or "core affect," that is, terminology that differs from the human emotion literature (Fraser, Weary, Pajor, \& Milligan, 1997). The relationship between affect and emotion is complex, containing a number of components still widely debated on a theoretical level (Barrett, 2012).

Studies of emotions in cows, as in other animals, tend to focus on just two easily-identifiable dimensions, namely valence (positive/negative or pleasant/unpleasant) and intensity (weak/strong), which vary independently of each other. It is reasonable to argue that the emphasis on these more basic unidimensional aspects of emotion in other animals is more a function of our own assumptions about their nature as well as limitations in measuring nonhuman emotions than it is an actual lack of complexity and subtlety in emotions in other animals (Désiré, Boissy, \& Veissier, 2002). Moreover, as emotions have cognitive, behavioral, autonomic, and subjective components that correlate with each other, there are established ways of identifying emotions in other animals that rely on directly measuring one or more of these elements and then inferring the presence of the others.

The literature on emotions in cows and other farmed animals is substantial and confirms that they experience a wide range of emotions and that some of those responses are quite complex. Basic emotions are the building blocks of more complex and sophisticated abilities. Thus, they will be reviewed briefly here. The more complex psychological phenomena, such as cognitive bias and emotional contagion, are more fully explored below as they suggest the capacity for more sophisticated mental phenomena, such as empathy.

Positive and negative emotional states. Studies indicate that cows express their internal subjective states with multiple behavioral and physiological changes. There have been numerous studies of fear and anxiety responses in cows. One of the most commonly used fear-testing paradigms for cows is the Open-Field (or Novel Arena) Test. Cows show demonstrable fear responses, such as increased latency to enter, defecation, vocalizations, and escape attempts when placed in this situation, but fear responses in this paradigm are not strongly correlated with fear in other situations. This overall finding demonstrates that fear responses in cows are shaped by diverse and complex factors and the idea of "general fear" in cows is an over-simplification (Forkman, Boissy, Meunier-Salaun, Canali, \& Jones, 2007). It would seem logical to argue that similar levels of oversimplification occur when interpreting positive emotional responses in cows. This conclusion should be kept in mind when reviewing other measures of emotion in cows (see below).

Eye white percentage. The relationship between changes in eye white percentage and cow emotions has been an area of significant research focus over the past few years. The percentage of visible eye white increases when the cow's upper eye lid is lifted, and the muscle responsible for this is controlled by the sympathetic postganglionic axons associated with emotion (Sandem \& Janczak, 2006). Changes in eye white perce ntage were initially conceptualized as expressions of general arousal, but they are now considered to be indicators of emotional valence.

Proctor and Carder (2015b) investigated whether visible eye white percentage was a measure of positive, low arousal state. They took focal samples of thirteen dairy cows during sessions of gentle petting. Visible eye white percentage decreased during the positive state and was significantly lower than pre- and post-test percentages. The authors concluded that visible eye whites were a valid predictor of positive emotional arousal in cows. 
An early study investigated changes in eye whites based on a frustration-contentedness axis among 24 randomly selected dairy cows. The cows were divided into two groups of twelve individuals. One group was exposed to the frustration-inducing stimulus of a rectangular wooden box that contained food, but was covered with plexiglass. The cows could see and smell the food through small holes, but could not access it. The other group of cows was exposed to an open wooden box containing food. Cows exposed to the frustrating stimulus had a higher percentage of visible eye whites than cows exposed to the pleasant stimulus. The eye white increases were also correlated with behavioral indicators of frustration, including aggressiveness, stereotypies, vocalizations, and head-shaking (Sandem, Braastad, \& Bøe, 2002).

Cow mothers who are separated from their calves also display increased eye whites, in addition to other behavioral signs of frustration. The eye white percentage significantly decreases when cows are reunited with their calves (Sandem \& Braastad, 2005). The work to date suggests that eye white percentage is a meaningful indicator of emotion, with more eye whites indicating fear and frustration and less eye white associated with positive feelings.

Other measures: nasal temperatures, ear posture, heart rate. Peripheral body temperatures have also been identified as an indicator of subjective emotional states in nonhuman mammals. In cows, this has been studied by measuring nasal temperatures. Proctor and Carder (2015a) investigated the effects of inducing a positive, low arousal emotional state on the nasal temperature of cows. The positive state was induced by stroking the cows in preferred regions to simulate allogrooming, an activity that has been shown to induce relaxation and lower heart rates in cows. Stroking resulted in significant decreases in average nasal temperatures. Since previous research has suggested that negative emotional states resulted in decreases in peripheral body temperature, their findings suggested that positive emotional states may lead to the same peripheral body temperature changes as negative emotional states (Proctor \& Carder, 2015a).

Ear posture may also be an indicator of emotional state in cows. Proctor and Carder (2014) conducted a study on a group of 13 cows to assess whether ear postures could predict a positive emotional state in cows who received the pleasant stimulus of gentle stroking by a human researcher with whom the cow had been habituated. The researchers completed a total of 381 fifteen-min focal observations. Each fifteen-minute sample included five minutes of baseline observations of the cow, five minutes of pleasant stroking, and five minutes of post-stroking observations. The videos were then analyzed to determine the amount of time cows spent in four pre-identified ear postures. Relaxed ear postures, which included a backward ear posture and a hanging ear posture, were more likely to be displayed for a longer duration while the cows were being gently stroked than during the pre- and post-tests. Less relaxed ear postures, which included the upright and forward ear postures, were more likely to be exhibited during pre- and post-tests. Additionally, more relaxed ear postures were performed during the poststroking samples than in pre-stroking samples (Proctor \& Carder, 2014).

In terms of physiological measures, cardiac rates are often used as indicators of emotional responses, but these can be unreliable. Heart rate variability, rather, has also been established as an important physiological indicator of distress in cows (Mohr, Langbein, \& Nürnberg, 2002). While additional confirmatory studies are needed, these studies suggest that cows provide important behavioral and physiological indications of their internal emotional states.

Play. Play behavior (or the lack thereof) can indicate positive and negative emotional states as well (Held \& Spinka, 2011). However, it should be noted that play behavior (which can take the form of object play, social play, or locomotor play) is anything but simple. Play is related to curiosity and innovation and, therefore, forms the basis for complex object-related and social abilities (Bateson, Bateson, \& Martin, 2013) in humans and other animals. It is also an expression of positive engagement with the environment and others. Most mammals (Burghardt, 2005; Holloway \& Suter, 2004) as well as some birds (Emery \& Clayton, 2015), amphibians, reptiles, fish (Burghardt, 2015), and some invertebrates (Zylinski, 2015) play. Play is most predominant in younger individuals. Play behavior is associated with endorphin release (Boissy et al., 2007) and the opportunity for social play is a potent reward in learning experiments (Humphreys \& Einon, 1981; Trezza, Baarendsem, \& Vanderschuren, 2010).

Cows engage in all forms of play found in mammals, including playing with objects such as balls, gamboling and running, and also social play with members of other species. Play-fighting, social licking, and play mounting in calves starts at around the second week of life and peaks at the age of four months (Reinhardt, 
Mutiso, \& Reinhardt, 1978). Play behavior in cows, as in other mammals, is a reflection of their circumstances. For instance, release from confinement increases the frequency of galloping and bucking (forms of locomotor play) in calves (Jensen, 1999). Likewise, pair housing and enhanced milk allowances increase play behavior in dairy calves (Jensen, Duve, \& Weary, 2015). Locomotor play was seen more in pair housed calves than control animals and social play, such as play fighting, was only seen between pair housed calves. Pair housing and enhanced feeding work synergistically to enhance play, and, thus, welfare (Jensen et al., 2015). On the other hand, earlier weaning and reduced milk allowance reduced playful running in calves (Krachun, Rushen, \& de Passillé, 2010). Not unexpectedly, pain in various forms decreases cow play behavior (Mintline et al., 2013). Therefore, cows who are deprived of needs or placed in negative situations show decreased play while an increase in play expresses the rewarding nature of good welfare.

Complex emotions. Complex emotional experiences, in the context of this paper, are defined as emotional responses which interact with other mental domains, such as cognition and sociality. The four areas to be reviewed are 1) emotional reactions to learning, 2) cognitive bias, 3) emotional contagion, and 4) social buffering. These more complex emotional experiences suggest the possibility of sophisticated levels of psychological capacities in cows, such as self-awareness and empathy.

Emotional reactions to learning. Emotional reactions to learning refer to the emotional effects of improving on a task separable from reactions to a reward itself. In other words, emotional reactions to learning have to do with the positive emotions and excitement that go with realizing one is controlling a situation and getting closer to a goal. Thus, an individual may become excited because he or she can control the delivery of a reward. It has been argued that this kind of complex emotional experience rests upon some level of self-awareness such as self-referral or self-agency (Hagen \& Broom, 2004). Hagen and Broom (2003) noted possible signs of pleasure and increased excitement (i.e., touching and engaging one of the human experimenters) in cows while performing a successful discrimination task. In a more direct test of this hypothesis, heifers were taught a maze task in a yoked paradigm so that both groups received reward but only one group controlled the delivery of rewards. They reached reliable successful performance within twelve trials. More to the point, the experimental animals got more excited than the control animals, not generally, but in precise temporal relation to experiencing operant learning. Because both the experimental group and the control group received cues as to how close they were to the reward, the results are not likely to be due to differences in sensitivity to cues. The authors speculated that the increased arousal in the experimental group was a direct result of the experimental animals' reaching a point of realizing their performance on the task improved, suggesting that they were emotionally reacting to a sense of self-efficacy in this situation. These findings have provocative implications for the question of selfawareness in cows.

Cognitive bias. Cognitive bias, the effects of negative or positive emotions on judgments and cognitive performance, has been an area of increasing interest in comparative psychology. Negative judgment biases involve responding negatively to ambiguous stimuli after a negative emotional experience and positive judgment biases, likewise, involve the effects of positive emotional experiences on cognition. Cognitive bias has been likened to a form of optimism and pessimism, suggesting a link between complex emotional states in humans and nonhuman animals. Judgment bias studies have been demonstrated in a wide range of nonhuman animals, including European starlings (Sturnus vulgaris; Matheson, Asher, \& Bateson, 2008), sheep (Ovis aries; Doyle, Fisher, Hinch, Boissy, \& Lee, 2010), pigs (Douglas, Bateson, Walsh, Bédué, \& Edwards, 2012), dogs (Brooks et al., 2010), capuchin monkeys (Cebus apella; Pomerantz, Terkel, Suomi, \& Paukner, 2012), bottlenose dolphins (Tursiops truncatus; Clegg, Rödel, \& Delfour, 2017), and honeybees (Apis mellifera; Bateson, Desire, Gartside, \& Wright, 2011).

Negative emotional states also appear to influence judgment abilities in dairy calves. Very young Holstein calves exhibited a negative judgment bias for at least $22 \mathrm{hrs}$ after hot-iron disbudding; the calves were less likely to approach ambiguous screen colors in two sessions after the procedure (Neave, Daros, Costa, von Keyserlingk, \& Weary, 2013). A second cognitive bias study investigated 13 mother-reared Holstein dairy calves' abilities to discriminate between red and white colors on a computer monitor. The calves were given rewards for approaching a white screen and were placed in a time-out for approaching a red screen. They also were given some trials in which ambiguous stimuli between white and red in color were presented. Before separation from their mothers, the calves' responded to those ambiguous stimuli as if they were white (i.e., a positive stimulus they approached) 
$72 \%$ of the time. After separation, however, this approach response dropped to $62 \%$, even though they continued to perform well with true white or red stimuli. The results suggested that, much like humans, when cows are distressed, they exhibit a relatively more negative response bias towards ambiguous stimuli (Daros, Costa, von Keyserlingk, Hötzel, \& Weary, 2014).

Emotional contagion. Emotions tend to influence more than one individual in a group. Moreover, they can be shared through a process known as emotional contagion, the arousal of emotion in one individual upon witnessing the same emotion in another individual (Hatfield, Cacioppo, \& Rapson, 1993). Emotional contagion is considered, by some investigators, to be a basic form of empathy, the ability to feel the emotional state of another from the other's perspective (de Waal, 2008). Emotional contagion may be the phylogenetically oldest level of empathy and a building block of more complex forms, as it is difficult to imagine the capacity for empathy without the ability to share or match emotional experience at some level. De Waal (2008) suggests that emotional contagion forms the basis of sympathetic concern (which involves some perspective-taking) and, ultimately, empathy-based altruism. Following this line of reasoning, it is important to determine if a species is capable of emotional contagion in order to ask questions about capacities for higher-level phenomena such as empathy and sympathy.

Emotional contagion, like other proximate psychological mechanisms, serves the ultimate purpose of providing a way for social animals to communicate about important circumstances that may affect the whole group and respond accordingly. It has been demonstrated in many socially complex taxa such as dogs (JolyMascheroni, Senju, \& Shepherd, 2008), wolves (Canis lupus; Romero, Ito, Saito, \& Hasegawa, 2014), great apes (Anderson, Myowa-Yamakoshi, \& Matsuzawa, 2004; Palagi, Norscia, \& Demuru, 2014) and pigs (Reimert, Bolhuis, Kemp, \& Rodenburg, 2013, 2014).

A series of studies on a form of emotional contagion mediated by olfactory cues has shown that when cows are exposed to stressed conspecifics they too show pronounced stress responses, such as decreased feeding and increased cortisol release. These responses were partly mediated by olfactory cues in the urine (Boissy et al., 1998).

Social buffering. Social mammals are not simply individuals who stay in proximity to each other. Instead, they are dependent upon interaction with the social group. Just as emotional contagion illustrates the connectedness of individuals within a social group, social buffering is a phenomenon that exemplifies the important emotional role that the social group plays for so many mammals, including cows. Social buffering refers to the fact that many social animals tend to react less intensively to negative stresses when they are in the presence of conspecifics (Kikusui, Winslow, \& Mori, 2006). And while emotional contagion can increase stress in individuals exposed to highly stressed conspecifics, for most social mammals the mere presence of unstressed conspecifics is calming. Social mammals, likewise, find it very stressful to be socially isolated (Kikusui et al., 2006).

Social buffering has been demonstrated in humans (Thorsteinsson, James, \& Gregg, 1998) and many nonhuman-primate species such as rhesus macaques (Macaca mulatta; Gilbert \& Baker, 2011), as well as guinea pigs (Cavia porcellus; Hennessy, Maken, \& Graves, 2000) and chickens (Gallus gallus; Edgar et al., 2015). As highly social mammals, cows demonstrate a strong response to their social circumstances, finding social isolation to be highly distressing and showing robust social buffering responses when they are together.

Tests of bulls used for beef show that they are less stressed during pre-slaughter handling if allowed to see or be in physical contact with their social group and that the effects were associated with the cohesiveness of the social group (Mounier, Veissier, Andanson, Delval, \& Boissy, 2006). Other studies have confirmed that social buffering can be effective in moderating stress when cows are allowed only visual contact (Boissy \& Le Neindre, 1990; Grignard, Boissy, Boivin, Garel, \& Le Neindre, 2000). Likewise, stressed cows will seek out other nonstressed cows (Ishiwata, Kilgour, Uetake, Eguchi, \& Tanaka, 2007), presumably for the stress-alleviating effects.

Young calves actively seek companion animals (Holm, Jensen, \& Jeppeson, 2002), suggesting they may derive social support benefits from the presence of other young conspecifics (Færevik, Jensen, \& Bøe, 2006). Unlike adult cows, calves prefer full physical contact with a partner over limited contact through the pen (Holm et al., 2002). But among adult cows, even a purely visual artificial "social" stimulus, such as a mirror, can be a source of social buffering. When heifers are weighed in the presence of a mirror with a side view or frontal view of themselves (facing "another" cow), the individuals with access to the front view had lowered heart rates 
compared to those who had access to a side view or no mirror (Piller, Stookey, \& Watts, 1999). (However, In general, social buffering effects are quite strong in calves and adult cows and demonstrate the complexity of factors that moderate emotional states in cows (Rault, 2012).)

There are numerous studies showing positive emotional and cognitive effects of pair- or group-housing over isolation in cows (e.g., Broom \& Leaver, 1978; Chua, Coenen, van Delen, \& Weary, 2002; De Paula Vieira, von Keyserlingk, \& Weary, 2010; Gaillard, Meagher, Keyserlingk, \& Weary, 2014; Vessier, Gesmier, Le Niendre, Gautier, \& Bertrand, 1994). For instance, Sato (1994) found that weaned calves that were licked more by other cows gained more weight and hypothesized that social licking leads to psychological stability in cows. And recently, Shin, Kang, and Seo (2017) found that paired housing, as opposed to single housing, enhanced the ability of pregnant heifers to deal with the stress of being switched to a novel diet. None of these findings are unexpected given the highly social nature of cows and the level of social complexity they possess, as discussed below. Social rearing and experiences, early on in life especially, would appear to be a necessary part of healthy psychological development in cows. These kinds of positive effects of social housing on learning might be argued to be a form of long-term social buffering.

Mother-calf emotional bonds. A large body of research has confirmed that mother cows and calves experience strong emotional bonds that form rapidly following birth and that the natural weaning process may take many months (von Keyserlingk \& Weary, 2007). Mother-calf bonding is partly dependent upon the ability of the mother to be able to lick the calf for several hours after birth (Hudson \& Mullord, 1977; Le Neindre \& D’Hour, 1989).

Likewise, mother cows experience distress when separated from their calves, and that stress appears to be alleviated upon reunion (Solano, Orihuela, Galina, \& Aguirre, 2007). An investigation of maternal bonding in dairy cattle found that mothers formed strong maternal bonds with their calves after just five minutes of contact following birth. Mothers who were separated from their calves after five minutes were able to recognize their own calves and engage in maternal behavior for up to $12 \mathrm{hrs}$ after separation. All mother cows showed signs of distress (walking around, urinating, vocalizing, butting, etc.) following separation from their calves. They stayed at one end of the paddock, vocalized continually, and displayed signs of high degrees of restlessness. After $24 \mathrm{hrs}$ following separation, mother cows continued to show signs of distress, but could no longer recognize their own calves (Hudson \& Mullord, 1977).

A number of studies confirm that both mother and calf experience greater distress with later separation. In a study of cow-calf separations after six hours, one day, and four days, calf emotional responses to separation were correlated with the day of separation (i.e., the amount of time they spent with their mother prior to separation). Mothers produced contact calls with a higher frequency and significantly more often for their calf when separated after four days than in the other two groups (Weary \& Chua, 2000). Contact calls between mothers and calves are critically important for maintaining their bond. Barfield, Tang-Martinez, and Trainer (1994) showed that 3 - 5 week old calves can recognize their mothers using vocal cues. And Marchant-Forde, Marchant-Forde, and Weary (2002) demonstrated that mothers and calves respond behaviorally to each other's calls and that calves respond preferentially to calls from their own mother over other adult cows.

In a recent study of the strong effects of the bond between calves and their mothers, calves were separated into two groups. One group had unrestricted contact with their mothers and were suckled while the other group was fed milk by an automatic feeder. Both groups were able to stay in their herd. When later tested for their reaction to challenging situations such as an isolation test and a confrontation with an unfamiliar cow, the motherreared calves showed more active efforts to get back to their mother and the herd and lower stress hormone levels when faced with an unfamiliar individual, than the feeder group (Wagner et al., 2013).

Summary of emotions. There is ample behavioral evidence that cows may possess not only a range of emotions but a level of complexity of emotions found in other mammals, who are generally recognized as being intelligent. This evidence includes play behavior and interactions between emotions and cognition in the forms of cognitive bias, emotional contagion, social buffering, and even emotional reactions to learning. 


\section{Personality}

Personality refers to "those characteristics of individuals that describe and account for temporally stable patterns of affect, cognition, and behavior" (Gosling, 2008, p. 986). Or put another way, personality is a set of traits that differ across individuals and are consistent over time. The concept of personality is based on the acceptance of individuality and, thus, has critical implications for how we regard other animals. Instead of viewing other animals as one-dimensional, interchangeable units within a group, population, or species, recognition of personality in other animals emphasizes their individuality. Furthermore, personality interacts with cognition and emotion, intimately shaping behavior and performance on a wide range of tasks (Carere \& Locurto, 2011).

In humans, there is broad agreement on a five-factor model of personality that includes the dimensions of openness, conscientiousness, extroversion, agreeableness, and neuroticism (e.g., McCrae \& Costa, 2008). Although some authors prefer to refer to "behavioral syndromes" or "temperament" in other animals (Reale, Reader, Sol, McDougall, \& Dingemanse, 2007), there is little distinction between these phenomena and personalities as observed and documented (Gosling, 2008).

Studies of nonhuman animals have shown that personality traits are ubiquitous in the animal kingdom; a wide range of fish (Mittelbach, Ballew, \& Kjelvik, 2014; Toms, Echevarria, \& Jouandot, 2010), birds (e.g., chickens, Gallus gallus domesticus, Favati, Leimar, \& Lovlie, 2014; zebra finches, Taeniopygia guttata, David, Auclair, \& Cezilly, 2011, Schuett, Dall, \& Royle, 2011; Japanese quail, Coturnix japonica, Miller, Garner, \& Mench, 2006), numerous mammal species (e.g., pigs, Sus domesticus, Marino \& Colvin, 2015; horses, Equus caballus, Hausberger, Bruderer, Le Scolan, \& Pierre, 2004; dogs, Canis familiaris, Svartberg, Tapper, Temrin, Radesäter, \& Thorman, 2005; cats, Felis catus, Bennett, Rutter, Woodhead, \& Howell, 2017; nonhuman primates, Freeman \& Gosling, 2010); reptiles and amphibians (Allard, Fuller,Torgerson-White, \& Murray, 2015; Burghardt, 2013), and invertebrates (Kralj-Fišer \& Schuett, 2014, for a review) show persistent individual differences that can be organized along core personality dimensions, many of which overlap with those found in humans (Gosling, 2008; Gosling \& John, 1999). Vonk, Weiss, and Kuczaj (2017) offer a comprehensive and upto-date review of personality in nonhuman animals.

Research on intra-individual trait consistency (i.e., personality structure) in cows is relatively new. Most studies in this field did not begin until the early 2000s. Moreover, they have been conducted primarily within the narrow framework of traits associated with increased agricultural production of cow products. These include weight gain, reproduction, or milk production (e.g., Hedlund \& Løvlie, 2015; Van Reenan et al., 2002). These factors have both shaped and limited the available range of direct data on cow personality traits.

Stability of behavioral characteristics in cows. Despite the limitations of the existing data on cow personality, several studies have established a clear pattern of stable intra-individual behavioral and physiological patterns in cows (Kovács et al., 2015; Lanier, Grandin, Green, Avery, \& McGee, 2000; MacKay, Haskell, Deag, \& van Reenan, 2014; Müller \& Schrader, 2005; van Reenen et al., 2002). Lanier et al. (2000) found evidence that individual reactivity to stress was predictable in cows. In this experiment, cows' reactivity to intermittent sounds and movements was significantly related to the temperament score assigned to them while they were being handled in an auction ring. Similarly, Van Reenen et al. (2002) assessed individual differences in response to udder preparation and mechanical milking at first milking, day 2, day 4, and day 130. Measures included kicking and stepping behavior, cortisol levels, heart rate, milk yield, flow rate, milking time, and residual milk following administration of oxytocin. Individual differences in behavioral responses to udder preparation were consistent from early milking to day 130. Individual physiological measures were also largely consistent over time. The authors concluded that early mechanical milking tends to be stressful for some cows and not for others. They also concluded that the mediating factor in dairy cows' responsiveness to being mechanically milked was related to "stable animal characteristics" (Van Reenan et al., 2002, p. 2557). Further early support for the presence of stable cow personality characteristics was found by Müller and Schrader (2005). Thirty-five dairy cows were assessed for long-term intra-individual consistency in behavioral and adrenocortical responses to an established stressor in cows (i.e., social separation). Although some habituation effects occurred, results indicated a high intra-individual consistency in all measured behavioral responses (walking, vocalization, defecation), as well as salivary cortisol levels, across two lactations. Further, principal component analysis indicated three primary behavioral patterns 
were exhibited: sociability, anxiety, and exploration. Two of these are analogous to human personality dimensions in the Five-Factor Model: Extraversion and Neuroticism (Müller \& Schrader, 2005), which have shown crossspecies generality in previous research (for discussion, see Gosling \& John, 1999).

Nervousness, fearfulness, and reactivity. It is important to note that high reactivity is an adaptive evolutionary trait in ungulates. However, because it has been associated with lower rates of milk production (Hedlund \& Løvlie, 2015) and lower rates of weight gain (Müller \& von Keyserlingk, 2006), it is often construed as a predominantly negative trait from an agricultural framework. This difference in the way reactivity is viewed is an illustration of how evolutionarily adaptive traits that allow animals to thrive in their natural environment are often those traits that animal users view as undesirable in an artificial environment, and how artificial breeding and handling is often at odds with the animal's basic nature.

Reactivity studies suggest that individual cows have consistent patterns of behavioral and physiological stress responses across time and situation. Hedlund and Løvlie (2015) investigated the association between behavioral responses to milking, responses to measures of personality (reactions to novel objects and to social isolation), and milk production during the first lactation among Swedish Red and White, as well as Holstein, dairy cows. Cows who stepped (a behavior indicative of nervousness, fear or discomfort) the most during milking and cows who spent more time facing the herd during social isolation produced less milk during their first lactation. Additionally, a higher vocalization rate during social separation was associated with lower milk production. The results suggested an overall trend that higher levels of nervousness in cows was associated with decreased milk production, but factors such as breed, behavioral indicators of nervousness, and the production measure all influenced the results, suggesting the relationship is not straightforward (Hedlund \& Løvlie, 2015).

Flight speed is another measure of fearfulness and reactivity in cows. It has therefore been investigated in relation to cow personality in multiple studies. In one study, cows were given a temperament score based on the velocity with which they entered and exited a restraining chute. Cows with scores of $\leq 3$ were categorized as having "adequate" temperaments, while cows with scores of > 3 were categorized as having "aggressive" temperaments. Cows with aggressive temperaments had significantly higher salivary cortisol levels, as well as reduced pregnancy rates, lower calf birth weights, and lower calf weaning weights (Cooke, Bohnert, Cappellozza, Mueller, \& DelCurto, 2012). However, flight speed can also be influenced by breed and sex in cows (Hoppe, Brandt, König, Erhardt, \& Gauly, 2010).

Behavioral reactivity level is so stable in cows that short-term personality assessments are useful predictors of their day-to-day behaviors. For instance, Mackay et al. (2014) conducted behavioral evaluations for forty days prior to exposing cows to a novel object. Cows who made more contact with the novel object had been observed as being less likely to lie down and having less variation in lying down behaviors than cows who made less contact with the novel object. Cows who were less fearful of humans also had fewer daily observed lying down behaviors. They also presented to the mechanical milker more frequently. However, age was also a factor, with older cows also showing more fearfulness.

Evidence suggests several physiological responses may be indicators of personality in cows. Eye whites, as discussed above, are a reliable indicator of emotion in cows. For instance, in beef cattle, eye white percentage was found to be an objective and quantifiable measure of temperament (Core, Widowski, Mason, \& Miller, 2009). A group of 48 heifers, 29 bulls, and 60 steers were video-recorded and photographed in a squeeze chute. Temperament scores were assigned on a scale of one to five, with one as calm and five as agitated, along with eye white percentages. These were compared with flight speeds that were assessed at a later time. Eye white percentage and chute temperament scores were significantly correlated for all three groups of cows.

Heart rate differences may also be an indicator of personality in cows (Cooke et al., 2012). Kovács et al. (2015) compared cow temperament with autonomic nervous system activity on both small- and large-scale farms. They found a higher basal sympathetic and lower vagal activity, and specifically, higher heart rates and heart rate variability, in cows who were categorized as "temperamental," rather than those categorized as "intermediate" or "calm" (Kovács et al., 2015).

Sociability and gregariousness. Despite research that confirms that cows form strong emotional bonds with kin and other conspecifics, there are limited data on sociability as a personality trait in cows. There are a few prominent exceptions, including the identification of sociability as a personality trait by Müller and Schrader (2005). The social complexity research, discussed below, certainly supports further inquiry into this area. For 
instance, there is evidence for reduction of stress when bonded associates are present (Walker, Arney, Waran, Handel, \& Phillips, 2015).

There is also a dearth of evidence regarding individual differences in cows with regard to cross-species sociality, though there is some evidence for acclimation to human handlers who provide positive handling experiences and interactions (Petherick, Doogan, Holroyd, Olsson, \& Venus, 2009), which is unfortunately nonnormative (i.e., branding, disbudding, rough handling of infant and adult cows; see Schwartzkopf-Genswein, Stookey, \& Welford, 1997; Stewart et al., 2013). Investigations to better understand individual differences in sociality and gregariousness in cows would be an important advancement in cow personality research.

Maternal protective behavior. Maternal protective behavior appears to be less related to individual personality in cows than other behavioral traits (Pérez-Torres et al., 2014). This may be because maternal protectiveness of offspring is so critically important that all cows are very high in this trait. For instance, in an investigation of individual differences in mother cows' reactions to an unfamiliar utility vehicle approaching mother and calf at $24 \mathrm{hrs}$ following birth, $99 \%$ of cows moved between the vehicle and their calves in a protective manner (Flörcke, Engle, Grandin, \& Deesing, 2012). Thus, there is little behavioral variability in maternal protectiveness.

Other areas of research relevant to personality. Arguably, a rich understanding of cow personalities has been limited by their use as commodities and their use can sometimes mask personality features. For instance, calves raised for milk and meat are fed diets that are very different from feral herds (Webb et al., 2014). They are fed a limited-choice diet that is calculated for the nutritional needs of an 'average calf.' However, much like humans and other animals, calves actually display a wide range of individual dietary preferences when given the opportunity to do so. Webb et al. (2014) investigated dietary preferences and related behaviors in 23 grouphoused Holstein-Fresian bull calves. Calves were provided milk replacer and a choice of four solid feed components. Offering choices in available food led to large variations in individual consumption. This variation may underlie some stable preferences that would add to our understanding of cow personalities.

Personality characteristics may also influence learning in cows. Reenen, Jensen, Bokkers, Schmitt, and Webb (2015) found high activity to be associated with low feed motivation. Therefore, personality may influence operant conditioning rates in cows. Finally, several studies have investigated the relationship between facial hair whorl patterns and personality in cows. Mixed results have been found. One study found no significant relationship between hair whorl and flight speed or hair whorl and weight gain, indicating hair whorl patterns in cows are limited in predicting reactive personalities (Olmos \& Turner, 2008). Conversely, another study found that cows with high and multiple hair whorls, who were standing with their day-old calves, reacted to an approaching, unfamiliar vehicle at a further distance than other cows. This may indicate a higher degree of vigilance than other cows (Flörcke et al., 2012).

Summary of personality. It is clear that cows, like other animals, have personalities, but while there are a number of studies that have demonstrated this, there is very little if anything known about personality structure (how their different personality traits relate to each other) and about some of the richer personality characteristics cows might possess that are not related to their use as commodities. This would be an important and compelling area of further research in more naturalistic settings that would allow greater expression of cow behavior.

\section{Social Complexity}

The social complexity hypothesis, attributed to Chance and Meade (1953) and Jolly (1966), has guided much of the scholarly inquiry into social complexity in nonhuman animals. This hypothesis suggests that the challenges encountered in the social environment place selective pressures on brain evolution. Humphrey (1976) noted that the social complexity hypothesis suggests there should be a positive relationship between social complexity and individual intelligence across species. However, Seyfarth and Cheney (2015) noted that it is difficult, in practice, to distinguish between social and nonsocial cognitive evolutionary pressures, as they often overlap.

Social complexity across species has conventionally been defined by the number of individuals in a social system and the relationship and differentiation among those individuals (Bergman \& Beehner, 2015). Bergman and Beehner (2015) propose a contemporary definition of social complexity that preserves the central role of 
cognition: “... social complexity should be measured as the number of differentiated relationships that members of a species have with conspecifics" (p. 205). Going beyond sheer group size, differentiated relationships are those that require recognizing and responding to differences across individuals (e.g., dominance roles, kinship, and other more complex multidimensional differences). Seyfarth and Cheney (2015) focused on the aspects of social cognition that relate to selection pressures arising from social interactions. They defined social cognition as knowledge about one's conspecifics. Further, they proposed that the complexity of social cognition can be measured by 'the individuals' knowledge of their own and other animals' social interactions and relationships" (Seyfarth \& Cheney, 2015, p. 3). A general definition of social complexity arguably includes the number of differentiated relationships, the degree of knowledge about conspecifics, and the knowledge of one's own and other animals' social interactions and relationships. Social complexity has been closely studied in a range of taxa and linked to cognitive and emotional abilities, and, therefore, social complexity, cognition and emotion should never be thought of as independent but rather as interacting domains of psychology.

Group size and structure. Group size is considered a basic dimension of social complexity in that the larger the group the more opportunities there are for relationships. Relationships, in turn, come with processing costs. According to Dunbar (1998), in general, for any given species, the number of ongoing social relationships is correlated with some components of brain size (e.g., neocortex), and, by implication, cognitive capacity. Currently, the evidence suggests that cows form large social groups with low levels of differentiation at the group level, but preferences for associations at the individual level.

The problem with estimating group size in cows is that they are often kept in artificial groupings. Thus, herd size is not necessarily natural under most of the circumstances experienced by cows being reared as food. Within this larger group, however, they appear to exercise choice as to who they affiliate with most. Boyland, Mlynski, James, Brent, and Croft (2016) investigated social network structure in dairy cows. A group of 110 lactating cows were observed over four one-month periods. Proximity was used to measure association. A positive correlation was found between proximity and other affiliative interactions. Cows also interacted with other cows with similar traits, such as gregariousness, breed, and number of lactations (Boyland et al., 2016). At the group level, there did not appear to be evidence of sub-communities, but rather of a large, integrated community. Another study of social networks of 20 to 50 animals showed that the herd is a strongly clustered network encompassing the majority of individual cows, but with many non-random attachment and avoidance relationships. However, there did not seem to be any individual cows who were strong nodes in the network (i.e., keeping subgroups together). Synchronicity, a measure of how frequently dyads of cows stay together during different activities, was influenced by whether two cows had grown up together and/or had spent their "dry period" before the last calving together. Moreover, affiliative relationships were more important for the network than agonistic ones (Gygax, Neisen, \& Wechsler, 2010). Gygax et al. (2010) found, in general, that most dairy cows live in clustered networks consisting of the majority of individuals in the group with the network held together by attachment and avoidance relationships.

Social networks have been argued to be affected by herd size in that relationships may be diluted (Kondo, Sekine, Okubo, \& Asahida, 1989) or more subgroups may form (Rubenstein, Sundaresan, Fischhoff, \& Saltz, 2007), with increasing group size. But once a herd is established, the relevance of agonistic interactions as descriptors of the cows' relationships and for their spatial structuring is weak because such interactions are rare and of low intensity (Gygax, Stolz, Louw, \& Neisen, 2006).

Hierarchies. Dominance hierarchies can, arguably, be viewed as a higher-order level of social complexity above and beyond group size. Dominance hierarchies serve to reduce group conflicts related to resource appropriation (O'Connell-Rodwell et al., 2011). Dominance hierarchies are widely present across several cognitively-complex mammal taxa, including African elephants (O'Connell-Rodwell et al., 2011), and bonobos (Surbeck, Mundry, \& Hohmann, 2011), and including farmed animals such as pigs (Puppe, Langbein, Bauer, \& Hoy, 2008) and goats (Miranda-de la Lama, Sepúlveda, Montaldo, María, \& Galindo, 2011). Cows, like many other ungulates, maintain a matrilineal social structure (Bouissou, Boissy, Le Neindre, \& Vessier, 2001). Allogrooming and proximity, two forms of affiliative behavior, are not strongly associated with strict dominance hierarchies of any kind, however (Val-Laillet, Guesdon, von Keyserlingk, de Passillé, \& Rushen, 2009).

Bonding and alliances. Social alliances and bonds are important in a wide variety of species. Maternalchild bonds are well-established in mammals, ranging from elephants to primates to mice. Attachment disruptions 
can lead to severe psychological and social impairments in both mother and offspring. For instance, mother guinea pigs demonstrate a passive, depressive-type response when separated from their pups across a wide range of infant ages (Schneider, Schiml, Deak, \& Hennessy, 2012). As discussed above in the section on social buffering, social support from conspecifics also appears to be important across many species for dealing with difficult circumstances. For example, pigs benefit from the presence of social support during stressful situations (Rodenburg, Bolhuis, Reimert, \& Kemp, 2014).

Dairy calves who were raised in more complex social groups tended to have increased coping abilities and higher capacities for coping with change (Costa, Daros, von Keyserlingk, \& Weary, 2014). Inexperienced cows grouped with experienced grazers displayed fewer vocalizations and less stomping, suggesting an affective component to this experience (Costa, Costa, Weary, Machado Filho, \& von Keyserlingk, 2016). Calves who were housed individually have shown greater distress in a novel environment and greater reluctance to approach an unfamiliar calf, in comparison to calves housed in pairs (Jensen \& Larsen, 2014). In tests of environmental novelty, calves housed in isolation were more likely to spend time running, defecating, and backing away, compared to those housed in pairs. Additionally, cows housed with age-mates were more reactive than cows housed with an older conspecific (Vieira, de Passillé, \& Weary, 2012). These findings are important given the increased understanding of the link between social stress and biological disease (Proudfoot, Weary, \& von Keyserlingk, 2012).

Cows form lasting social bonds, both with their offspring and their herd members. Calves on pasture often form sub-groups based on familiarity and kinship (Kiley-Worthington \& De La Plain, 1983; Sato, Woodgush, \& Wetherill, 1987). Mother rearing has an important and unique influence on cow social and psychological well-being, as well as measures of learning and cognition (as described above). One study found that calves who were given continual access to their mothers in their first 12 weeks of life displayed more exploration and activity when isolated in a test area, in comparison to calves who were reared in isolation. Calves with permanent and continual access to their mothers and their herds displayed increased sociality and decreased physiological stress responses (Wagner et al., 2015). Other studies have yielded similar findings. When exposed to a fifteen-minute isolation test at 43 days of age, calves reared by their mothers, rather than with an automatic feeder, displayed more escape behaviors and increased attempts to reunite with their herds. Mother-reared calves also displayed increased sociality with an unfamiliar calf at 90 days of age, compared with calves reared in isolation (Wagner et al., 2013). Mother cows also have demonstrated an ability to adapt their maternal behaviors to the needs of their calves. For instance, calves with low birth weights are provided more maternal protection and increased time nursing (Stěhulová et al., 2013).

Social learning. One of the ways that social species take advantage of group living is through social (observational) learning - observing conspecifics' behavior and its consequences in order to avoid timeconsuming and sometimes hazardous "trial and error" learning. Social learning appears to be a form of deferred imitation (action learning) or emulation (results learning), serving as a mechanism for the transmission of learned behaviors over stretches of time (i.e., culture). But imitation and emulation are only two of a number of potential mechanisms for social learning (Zentall, 2012) and careful experimentation is needed to differentiate among the many cognitive bases for social learning in other animals. Nevertheless, the general capability for social learning is one of enormous significance in the evolution of complex behavior in vertebrates.

Many animals engage in social learning (see Galef \& Laland, 2005), including chimpanzees (e.g., Bering, Bjorklund, \& Ragan, 2000; Whiten, 1998; Yamamoto, Humley, \& Tanaka, 2013), orangutans (Pongo pygmaeus; Bering et al., 2000), capuchin monkeys (Cebus apella; Ottoni \& Mannu, 2001), and other social mammals, as well as birds, such as ravens (Bugnyar \& Kotrschal, 2002), quail (Köksal \& Domjan, 1998), and chickens (Nicol, 2006), and fish (e.g., nine-spined sticklebacks, Pungitius pungitius; Kendal, Rendell, Pike, \& Laland, 2009), and reptiles (bearded dragon, Pogona vitticeps; Kis, Huber, \& Wilkinson, 2015).

Studies of housing differences in cows provide evidence that they engage in social learning, particularly when reared under natural social circumstances. For instance, cows who that have never grazed before begin to show normal grazing behaviors more quickly when they are grouped with experienced grazers than when grouped with inexperienced grazers (Costa et al., 2016). Also, cows housed with full social contact with a peer engage in more social behaviors than calves housed individually, with limited contact through bars (Duve \& Jensen, 2012). 
Moreover, housing studies like those reviewed above (see "Bonding and Alliances") have also suggested potential psychological benefits for cows that have the opportunity for social learning.

Summary of social complexity. Given a general definition of social complexity as the number of differentiated relationships, the knowledge about conspecifics, and the knowledge of one's own and other animals' social interactions and relationships, cows display broad parameters of social complexity in empirical studies. They have demonstrated knowledge about conspecifics and the exchange of relevant social knowledge with conspecifics. Through dominance hierarchies and affiliative bonds, they have demonstrated knowledge about conspecifics and of their own social interactions with them.

\section{Conclusion}

In this paper we have identified a number of findings from the scientific literature on cow learning, memory, emotions, personality, and social complexity (collectively cow psychology) showing that cows are far more sophisticated and sensitive than the simple grazers they are perceived to be by many members of our own species (Herzog, 2010; Joy, 2009).

These ideologies held by humans, which are incongruent with extant scientific understanding, have been largely maintained by powerful economic and political forces. Moreover, the body of scientific knowledge has been similarly shaped and limited by this ideology. The current literature demonstrates that cows:

1) are able to make sophisticated discriminations among not only objects but humans and conspecifics;

2) possess not just simple emotions, but several emotional capacities, such as cognitive judgment bias and emotional contagion;

3) show an apparent emotional reaction to learning which may reflect a sense of self-agency similar to some other mammals;

4) have distinct personalities;

5) exhibit several dimensions of social complexity, including social learning.

Moreover, there are also a number of compelling questions demanding investigation in cows under natural and non-invasive conditions. This summary might serve as a roadmap for future investigations of cow psychology in the hope that we can come to know who they are as complex individuals instead of commodities.

\section{References}

Adamczyk, K., Górecka-Bruzda, A., Nowicki, J., Gumułka, M., Molik, E., Schwarz, T., \& Klocek, C. (2015). Perception of environment in farm animals. A review. Annals of Animal Science, 15, $565-589$.

Albright, J. L., Kilgour, R., \& Whittlestone, W. G. (1982). The solving of problems by dairy animals on the basis of extrapolation. Proceedings of the International Dairy Congress, 1, 38 - 39.

Allard, S., Fuller, G., Torgerson-White, L., \& Murray, A. (2015). Personality in turtles. Journal of Applied Animal Welfare Science, 18, S62-S72.

Anderson, M. C., Myowa-Yamakoshi, M., \& Matsuzawa, T. (2004). Contagious yawning in chimpanzees. Proceedings of the Royal Society B, 27 (Suppl 6), S468 - S470.

Bailey, D. W., Rittenhouse, L. R., Hart, R. H., \& Richards, R. W. (1989). Characteristics of spatial memory in cattle. Applied Animal Behaviour Science, 23, 331-340.

Balda, R. P., \& Kamil, A. C. (2002). Spatial and social cognition in corvids: An evolutionary approach. In M. Bekoff, C. Allen, \& G. M. Burghardt (Eds.), The cognitive animal (pp.129 - 134). Cambridge, MA: MIT Press.

Baldwin, B. A. (1981). Shape discrimination in sheep and calves. Animal Behaviour, 29, 830 - 834. 
Baldwin, B. A., \& Start, I. B. (1978). Methods for the study of illumination preferences in sheep and calves. Journal of Physiology, 284, $13-14$.

Baldwin, B. A., \& Start, I. B. (1981). Sensory reinforcement and illumination preference in sheep and calves. Proceedings of the Royal Society of London Series B, 211, 513 - 526.

Barfield, C. H., Tang-Martinez, Z., \& Trainer, J. M. (1994). Domestic calves (Bos taurus) recognize their own mothers by auditory cues. Ethology, 97, $257-264$.

Barrett, L. F. (2012). Emotions are real. Emotion, 12, 413 - 429.

Bateson, P., Bateson, P. P. G., \& Martin, P. (2013). Play, playfulness, creativity and innovation. Cambridge, UK: Cambridge University Press.

Bateson, M., Desire, S., Gartside, S. E., \& Wright, G. A. (2011). Agitated honeybees exhibit pessimistic cognitive biases. Current Biology, 21, 1070 - 1073.

Bekoff, M. (2005). The question of animal emotions: An ethological perspective. In F. D. McMillan (Ed.), Mental health and well-being in animals (pp. 15 - 28). Ames, Iowa: Blackwell.

Bennett, P. C., Rutter, N. J., Woodhead, J. K., \& Howell, T. J. (2017). Assessment of domestic cat personality, as perceived by 416 owners, suggests six dimensions. Behavioural Processes, 141, $273-283$.

Bensky, M. K., Gosling, S. D., \& Sinn, D. L. (2013). The world from a dog's point of view: A review and synthesis of dog cognition research. Advances in the Study of Behavior, 45, 209 - 406.

Bergman, T. J., \& Beehner, J.C. (2015). Measuring social complexity. Animal Behaviour, 103, 203 - 209.

Bering, J. M., Bjorklund, D. F., \& Ragan, P. (2000). Deferred imitation of object-related actions in human-reared juvenile chimpanzees and orangutans. Developmental Psychobiology, 36, $218-232$.

Bird, L. R., Roberts, W. A., Abroms, B., Kit, K. A., \& Crupi, C. (2003). Spatial memory for food hidden by rats (Rattus norvegicus) on the radial maze: Studies of memory for where, what, and when. Journal of Comparative Psychology $117,176-187$.

Boissy, A., \& Le Neindre, P. (1990). Social influences on the reactivity of heifers: Implications for learning abilities in operant conditioning. Applied Animal Behavior Science, 25, $149-165$.

Boissy, A., Manteuffel, G., Bak Jensen, M., Oppermann Mor, R., Spruijt, B., Keeling, L. J., ...Langbein, J. (2007). Assessment of positive emotions in animals to improve their welfare. Physiology and Behavior, 92, 375 - 397.

Boissy. A, Terlouw, C., \& Le Neindre, P. (1998). Presence of cues from stressed conspecifics increases reactivity to a versive events in cattle: Evidence for the existence of alarm substances in urine. Physiology and Behavior, 63, 489-495.

Bomzon, A. (2011). Pain and stress in cattle: A personal perspective. Israel Journal of Veterinary Medicine, 66, 12 - 20.

Boris, L. M. (2011). The food-borne ultimatum: Proposing federal legislation to create humane living conditions for animals raised for food in order to improve human health. Journal of Law and Health, 24, 285.

Bouissou, M. F., Boissy, A., Le Neindre, P., \& Vessier, I. (2001). The social behaviour of cattle. In L. J. Keeling \& H. W. Gonyou (Eds.), Social behavior in farm animals (pp. 113 - 145). New York, NY: CABI Publishing.

Boyland, N. K., Mlynski, D. T., James, R., Brent, L. J., \& Croft, D. P. (2016). The social network structure of a dynamic group of dairy cows: From individual to group level patterns. Applied Animal Behaviour Science, 174, $1-10$.

Broom, D. M., \& Leaver, J. D. (1978). Effects of group-rearing or partial isolation on later social behaviour of calves. Animal Behaviour, 26, 1255-1263.

Brown, C. (2015). Fish intelligence, sentience, and ethics. Animal Cognition, 18, 1 - 17.

Brydges, N. M., Leach, M., Nicol, K., Wright, R., \& Bateson, M. (2011). Environmental enrichment induces optimistic cognitive bias in rats. Animal Behaviour, 81, 169-175.

Bugnyar, T., \& Kotrschal, K. (2002). Observational learning and the raiding of food caches in ravens, Corvus corax: Is it 'tactical' deception? Animal Behaviour, 64, 185 - 195.

Burghardt, G. M. (2005). The genesis of animal play. Cambridge, MA: MIT Press.

Burghardt, G. M. (2013). Environmental enrichment and cognitive complexity in reptiles and amphibians: Concepts, review, and implications for captive populations. Applied Animal Behaviour Science, 147, 286 - 298.

Burghardt, G. (2015). Play in fishes, frogs and reptiles. Current Biology, 25, R9 - R10.

Carere, C., \& Locurto, C. (2011). Interaction between animal personality and animal cognition. Current Zoology, 57, $491-$ 498.

Chance, M. R., \& Mead, A. P. (1953). Social behaviour and primate evolution. In Symposia of the Society for Experimental Biology, 7, $395-439$.

Chua, B., Coenen, E., Van Delen, J., \& Weary, D. M. (2002). Effects of pair versus individual housing on the behavior and performance of dairy calves. Journal of Dairy Science, 85, 360 - 364.

Clegg, I. L., Rödel, H. G., \& Delfour, F. (2017). Bottlenose dolphins engaging in more social affiliative behaviour judge ambiguous cues more optimistically. Behavioural Brain Research, 322, 115 - 122. 
Cooke, R., Bohnert, D., Cappellozza, B., Mueller, C., \& DelCurto, T. (2012). Effects of temperament and acclimation to handling on reproductive performance of Bos taurus beef females. Journal of Animal Science, 90, 3547 - 3555.

Core, S., Widowski, T., Mason, G., \& Miller, S. (2009). Eye white percentage as a predictor of temperament in beef cattle. Journal of Animal Science, 87, 2168 - 2174.

Costa, J. H. C., Costa, W. G., Weary, D. M., Machado Filho, L. C. P., \& von Keyserlingk, M. A. G. (2016). Dairy heifers benefit from the presence of an experienced companion when learning how to graze. Journal of Dairy Science, 99, $562-568$

Costa, J. H. C., Daros, R. R., von Keyserlingk, M. A. G., \& Weary, D. M. (2014). Complex social housing reduces food neophobia in dairy calves. Journal of Dairy Science, 97, $7804-7810$.

Coulon, M., Baudoin, C. \& Heyman, Y., \& Deputte, B.L. (2011). Cattle discriminate between familiar and unfamiliar conspecifics by using only head visual cues. Animal Cognition, 14, $279-290$.

Coulon, M., Deputte, B. L., Heyman, Y. \& Baudoin, C. (2009). Individual recognition in domestic cattle (Bos taurus): Evidence from 2D-images of heads from different breeds. PLoS One, 4, e4441.

Coulon, M., Deputte, B. L., Heyman, Y., Richard, C., Delatouche, L., \& Baudoin, C. (2007). Visual discrimination by heifers (Bos taurus) of their own species. Journal of Comparative Psychology, 121, $198-204$.

Croney, C. C., Adams, K. M., Washington, C. G., \& Stricklin, W. R. (2003). A note on visual, olfactory and spatial cue use in foraging behaviour of pigs: Indirectly assessing cognitive abilities. Applied Animal Behaviour Science, 83, 303 308.

Daros, R. R., Costa, J. H., von Keyserlingk, M. A., Hötzel, M. J., \& Weary, D. M. (2014). Separation from the dam causes negative judgement bias in dairy calves. PLoS One, 9, e98429.

David, M., Auclair, Y., \& Cezilly, F. (2011). Personality predicts social dominance in female zebra finches, Taeniopygia guttata, in a feeding context. Animal Behaviour, 81, $219-224$.

Decker, J. E., McKay, S. D., Rolf, M. M., Kim, J., Molina Alcalá, A, Sonstegard, T. S., Hanotte, O., Götherström, A., Seabury, C. M., \& Praharani, L. (2014). Worldwide patterns of ancestry, divergence, and admixture in domesticated cattle. PLoS Genetics 10, e1004254.

De Souza. A. S., Jansen, J., Tempelman, R. J., Mendl, M. \& Zanella, A. J. (2006). A novel method for testing social recognition in young pigs and the modulating effects of relocation. Applied Animal Behavior Science, 99, 77 - 87.

Désiré, L., Boissy, A., \& Veissier, I. (2002), Emotions in farm animals: A new approach to animal welfare in applied ethology. Behavioural Processes 60, $165-180$.

De Paula Vieira, A., von Keyserlingk, M. A. G., \& Weary, D. M. (2010). Effects of pair versus single housing on performance and behavior of dairy calves before and after weaning from milk. Journal of Dairy Science, 93, 3079 3085.

de Waal, F. B. M. (2008). Putting the altruism back into altruism: The evolution of empathy. Annual Review of Psychology, $59,279-300$.

Douglas, C., Bateson, M., Walsh, C., Be'due' A., \& Edwards, S. A. (2012). Environmental enrichment induces optimistic cognitive biases in pigs. Applied Animal Behavior Science, 139, 65 - 73.

Doyle, R. E., Fisher, A. D., Hinch, G. N., Boissy, A., \& Lee, C. (2010). Release from restraint generates a positive judgement bias in sheep. Applied Animal Behavior Science, 122, $28-34$.

D'Silva, J. (2006). Adverse impact of industrial animal agriculture on the health and welfare of farmed animals. Integrative Zoology, $1,53-58$.

Dunbar, R. I. (1998). The social brain hypothesis. Evolutionary Anthropology, 6, 178 - 190.

Duve, L. R., \& Jensen, M. B. (2012). Social behavior of young dairy calves housed with limited or full social contact with a peer. Journal of Dairy Science, 95, 5936 - 5945.

Edgar, J., Held, S., Paul, E., Pettersson I., I'Anson Price, R., \& Nicol, C. (2015). Social buffering in a bird. Animal Behaviour, 105, $11-19$.

Emery, N. J., \& Clayton, N. S. (2015). Do birds have the capacity for fun? Current Biology 25, R16 - R20.

Enriquez, D., Hotzel, M., \& Ungerfeld, R. (2011). Minimising the stress of weaning of beef calves: A review. Acta Veterinaria Scandinavica, 53, 28.

Færevik, G., Jensen, M. B., \& Bøe, K. E. (2006). Dairy calves social preferences and the significance of a companion animal during separation from the group. Applied Animal Behaviour Science, 99, 205 - 221.

Fagot, J. (2000). Picture perception in animals. East Sussex, England: Psychology Press Ltd.

Faulkner, P., \& Weary, D. M. (2000). Reducing pain after dehorning in dairy calves. Journal of Dairy Science, 83, 2037 2041.

Favati, A., Leimar, O., \& Lovlie, H. (2014). Personality predicts social dominance in male domestic fowl. PLoS One, 9, e103535. 
Flörcke, C., Engle, T. E., Grandin, T., \& Deesing, M. J. (2012). Individual differences in calf defense patterns in Red Angus beef cows. Applied Animal Behaviour Science, 139, $203-208$.

Forkman, B., Boissy, A., Meunier-Salaün, M. C., Canali, E., \& Jones, R. B. (2007). A critical review of fear tests used on cattle, pigs, sheep, poultry and horses. Physiology \& Behavior, 92, 340-374.

Fraser, D., Weary, D. M., Pajor, E. A., \& Milligan, B. (1997). A scientific conception of animal welfare that reflects ethical concerns. Animal Welfare, 6, $187-205$.

Freeman, H. D., \& Gosling, S. D. (2010). Personality in nonhuman primates: A review and evaluation of past research. American Journal of Primatology, 72, $653-671$.

Gaillard, C., Meagher, R. K., von Keyserlingk, M. A. G., \& Weary, D. M. (2014). Social housing improves dairy calves' performance in two cognitive tests. PLoS ONE, 9, e90205.

Galef, B. G., \& Laland, K. N. (2005). Social learning in animals: Empirical studies and theoretical models. Bioscience, 55, $489-499$.

Garber, P. A., \& Dolins, F. L. (2014). Primate spatial strategies and cognition: Introduction to this special issue. American Journal of Primatology, 76, $393-398$.

Gilbert, B. J., \& Arave, C. W. (1985). Ability of cattle to distinguish among different wavelengths of light. Journal of Dairy Science, $69,825-832$.

Gilbert, M. H., \& Baker, K. C. (2011). Social buffering in adult male rhesus macaques (Macaca mulatta): Effects of stressful events in single vs. pair housing. Journal of Medical Primatology, 40, $71-78$.

Ginane, C., Baumont, R., \& Favreau-Peigne, A. (2011). Perception and hedonic value of basic tastes in domestic ruminants. Physiology and Behavior, 104, $666-674$.

Gosling, S. (2008). Personality in nonhuman animals. Social and Personality Psychology Compass, 2, 985 - 1001.

Gosling, S., \& John, O. P. (1999). Personality dimensions in nonhuman animals. Current Directions in Psychological Science, 8, $69-75$.

Grandin, T. (2015). Improving animal welfare: A practical approach $\left(2^{\text {nd }}\right.$ ed). Oxfordshire, UK: CABI.

Grignard, L., Boissy, A., Boivin, X., Garel, J. P., \& Le Neindre, P. (2000). The social environment influences the behavioral responses of beef cattle to handling. Applied Animal Behaviour Science, 68, $1-11$.

Gunderson, R. (2013). From cattle to capital: Exchange value, animal commodification, and barbarism. Critical Sociology, 39, $259-275$.

Gygax, L., Neisen, G., \& Wechsler, B. (2010). Socio-spatial relationships in dairy cows. Ethology, 116, 10 - 23.

Gygax, L., Stolz, S., Louw, M., \& Neisen, G. (2006). Correlations between various social behaviour patterns and proximity in dairy cows. KTBL-Schrift, 448, 61-70.

Hagen, K., \& Broom, D. M. (2003). Cattle discriminate between individual familiar herd members in a learning experiment. Applied Animal Behaviour Science, 82, 13 - 28.

Hagen, K., \& Broom, D. M. (2004). Emotional reactions to learning in cattle. Applied Animal Behaviour Science, 85, 203 213.

Hatfield, E., Cacioppo, J., Rapson, R. L. (1993). Emotional contagion. Current Directions in Psychological Science, 2, 96 99.

Hausberger, M., Bruderer, C., Le Scolan, N., \& Pierre, J. S. (2004). Interplay between environmental and genetic factors in temperament/personality traits in horses (Equus caballus). Journal of Comparative Psychology, 118, $434-446$.

Hedlund, L., \& Løvlie, H. (2015). Personality and production: Nervous cows produce less milk. Journal of Dairy Science, $98,5819-5828$.

Heffner, R. S., \& Heffner, H. (1983). Hearing in large mammals: Horses (Equus caballus) and cattle (Bos taurus). Behavioral Neuroscience, 97, $299-309$.

Held, S. D. E., \& Spinka, M. (2011). Animal play and animal welfare. Animal Behaviour, 81, 891 - 899.

Hemsworth, P. H., Verge, J., \& Coleman, G. J. (1996). Conditioned approach avoidance responses to humans: The ability of pigs to associate feeding and aversive social experiences in the presence of humans with humans. Applied Animal Behaviour Science, 50, $71-82$.

Hennessy, M. B., Maken, D. S., \& Graves, F. C. (2000). Consequences of the presence of the mother or unfamiliar adult female on cortisol, ACTH, testosterone and behavioral responses of periadolescent guinea pigs during exposure to novelty. Psychoneuroendocrinology, 25, 619-632.

Herzog, H. (2010). Some we love, some we hate, some we eat: Why it's so hard to think straight about animals. New York, NY: Harper.

Hirata, M., \& Takeno, N. (2014). Do cattle (Bos taurus) retain an association of a visual cue with a food reward for a year? Animal Science Journal, 85, 729 - 734.

Hirata, M., Tomita, C., \& Yamada, K. (2016). Use of a maze test to assess spatial learning and memory in cattle: Can cattle traverse a complex maze? Applied Animal Behaviour Science, 180, 18 - 25. 
Holloway, K. S., \& Suter, R. B. (2004). Play deprivation without social isolation: Housing controls. Developmental Psychobiology, 44, $58-67$.

Holm, L., Jensen, M. B., \& Jeppesen, L. L. (2002). Calves' motivation for access to two different types of social contact measured by operant conditioning. Applied Animal Behaviour Science, 79, 175 - 194.

Hoppe, S., Brandt, H., Konig, S., Erhardt, G., \& Gauly, M. (2010). Temperament traits of beef calves measured under field conditions and their relationships to performance. Journal of Animal Science, 88, 1982 - 1989.

Hotzel, M. J., Machado Filho, L. C. P., Yunes, M. C., \& Silveira, M. C. (2005). Influence of aversive handling on milk production in Dutch cows. Revista Brasileira de Zootecnia, 34, 1278 - 1284.

Huber, L., Apfalter, W., Steurer, M., \& Prossinger, H. (2005). A new learning paradigm elicits fast visual discrimination in pigeons. Journal of Experimental Psychology: Animal Behavior Processes, 31, 237 - 246.

Hudson, S. J., \& Mullord, M. M. (1977). Investigations of maternal bonding in dairy cattle. Applied Animal Ethology, 3, $271-276$.

Humphrey, N. K. (1976). The social function of intellect. Growing Points in Ethology, 303 - 317.

Humphreys, A. P., \& Einon, D. F. (1981). Play as a reinforcer for maze-learning in juvenile rats. Animal Behavior, 29, 259270.

Ishiwata, T., Kilgour, R. J., Uetake, K., Eguchi, Y., \& Tanaka, T. (2007). Choice of attractive conditions by beef cattle in a Y-maze just after release from restraint. Journal of Animal Science, 85, 1080 - 1085.

Jensen, M. B. (1999). Effects of confinement on rebounds of locomotor behaviour of calves and heifers, and the spatial preferences of calves. Applied Animal Behaviour Science, 62, 43 - 56.

Jensen, M. B., Duve, L. R., \& Weary, D. M. (2015). Pair housing and enhanced milk allowance increase play behavior and improve performance in dairy calves. Journal of Dairy Science, 98, 2568 - 2575.

Jensen, M. B., \& Larsen, L. E. (2014). Effects of level of social contact on dairy calf behavior and health. Journal of Dairy Science, 97, $5035-5044$.

Johnsen, J. F., Ellingsen, K., Grøndahl, A. M., Bøe, K. E., Lidfors, L., \& Mejdell, C. M. (2015). The effect of physical contact between dairy cows and calves during separation on their post-separation behavioural response. Applied Animal Behaviour Science, 166, 11 - 19.

Jolly, A. (1966). Lemur social behavior and primate intelligence: Step from prosimian to monkey intelligence probably took place in a social context. Science, $153,501-506$.

Joly-Mascheroni, R. M., Senju, A., \& Shepherd, A. (2008). Dogs catch human yawns. Biology Letters, 4, 446 - 448.

Joy, M. (2009). Why we love dogs, eat pigs and wear cows. San Francisco, CA: Conari Press.

Kehoe, E. J. (2008). Discrimination and generalization. In J. Byrne (Ed.), Learning and memory: A comprehensive reference (pp. 123 - 150). Oxford, UK: Elsevier.

Kendal, J. R., Rendell, L., Pike, T. W., \& Laland, K. N. (2009). Nine-spined sticklebacks deploy a hill-climbing social learning strategy. Behavioral Ecology, 20, $238-244$.

Ksiksi, T., \& Laca, E. A. (2002). Cattle do remember locations of preferred food over extended periods. Asian Australian Journal of Animal Sciences, 15, $900-904$.

Kikusui, T., Winslow, J. T., \& Mori, Y. (2006). Social buffering: Relief from stress and anxiety. Philosophical Transactions of the Royal Society B, 361, $2215-2228$.

Kiley-Worthingthon, M. \& De La Plain, D. (1983). The social organization of the herd. In Fölsch, D. W. (Ed.), The behaviour of beef suckler cattle (Bos taurus) (pp. 105 - 123). Zürich, Switzerland: Verlag Basel.

Kiley-Worthingthon, M., \& Savage, P. (1978). Learning in dairy cattle using a device for economical management of behaviour. Applied Animal Behavior Ethology, 4, 119 - 124.

Kilgour, R. (1981). Use of the Hebb-Williams closed-field test to study the learning of Jersey cows. Animal Behavior, 29, $850-860$.

Kis, A., Huber, L., \& Wilkinson, A. (2015). Social learning by imitation in a reptile (Pogona vitticeps). Animal Cognition, $18,325-331$.

Knowles, T. G., Warriss, P. D., \& Vogel, K. (2014). Stress physiology of animals during transport. In T. Grandin, (Ed.), Livestock handling and transport: Theories and applications (pp. 399 - 484). Wallingford, UK: CABI Publishing.

Köksal, F., \& Domjan, M. (1998). Observational conditioning of sexual behavior in the domesticated quail. Animal Learning \& Behavior, 26, $427-432$.

Kondo, S., Sekine, J., Okubo, M., \& Asahida, Y. (1989). The effects of group size and space allowance on the agonistic and spacing behaviour of cattle. Applied Animal Behaviour Science, 24, 127 - 135.

Kovács, L., Kézér, F. L., Tozsér, J., Szenci, O., Póti, P., \& Pajor, F. (2015). Heart rate and heart rate variability in dairy cows with different temperament and behavioural reactivity to humans. PLoS One, 10, e0136294.

Kovalčik, K., \& Kovalčik, M. (1986). Learning ability and memory testing in cattle of different ages. Applied Animal Behaviour Science, 15, 27 - 29. 
Krachun, C., Rushen, J., \& de Passillé, A. M. (2010). Play behaviour in dairy calves is reduced by weaning and by a low energy intake. Applied Animal Behavior Science, 122, $71-76$.

Kralj- Fišer, S., \& Schuett, W. (2014). Studying personality variation in invertebrates: Why bother? Animal Behaviour, 91, $41-52$.

Laca, E. A. (1998). Spatial memory and food searching mechanisms of cattle. Journal of Range Management, 51, 370 - 378.

Lanier, J. L., Grandin, T., Green, R. D., Avery, D., \& McGee, K. (2000). The relationship between the reaction to sudden, intermittent movements and sounds, and temperament. Journal of Animal Science, 78, 1467 - 1474.

Lee, C., Henshall, J. M., Wark, T. J., Crossman, C., C., Reed, M. T., Brewer, H. G., O’Grady, J., \& Fisher, A. D. (2009). Associative learning by cattle to enable effective and ethical virtual fences. Applied Animal Behaviour Science, 119, $15-22$.

Le Neindre, P., \& D'Hour, P. (1989). Effects of a postpartum separation on maternal responses in primiparous and multiparous cows. Animal Behaviour, 37, $166-168$.

Liberman, N., \& Trope, Y. (2014). Traversing psychological distance. Trends in Cognitive Sciences, 18, 364 - 369.

MacKay, J. R. D., Haskell, M. J., Deag, J. M., \& van Reenan, K. (2014). Fear responses to novelty in testing environments are related to day-to-day activity in the home environment in dairy cattle. Applied Animal Behaviour Science, 152, $7-16$.

Marchant-Forde, J. N., Marchant-Forde, R. M., \& Weary, D. M. (2002). Responses of dairy cows and calves to each other's vocalizations after early separation. Applied Animal Behaviour Science, 78, $19-28$.

Marino, L., \& Colvin, C. M. (2015). Thinking pigs: A comparative review of cognition, emotion and personality in Sus domesticus. International Journal of Comparative Psychology, 28, 2168 - 3344.

Matheson, S. M., Asher, L., \& Bateson, M. (2008). Larger, enriched cages are associated with "optimistic" response biases in captive European starlings (Sturnus vulgaris). Applied Animal Behaviour Science, 109, 374 - 383.

Matsuzawa, T. (2001). Primate origins of human cognition and behavior. Tokyo, Japan: Springer.

McComb, K., Moss, C., Sayialel, S., \& Baker, L. (2000). Unusually extensive networks of vocal recognition in African elephants. Animal Behaviour, 59, $1103-1109$.

McCrae, R. R., \& Costa, P. T. (2008). The five-factor theory of personality. In O. P. John, R. W. Robins, \& L. A. Pervin (Eds.), Handbook of personality (pp. 159 - 181). New York, NY: Guildford Press.

McTavish, E. J., Decker, J. E., Schnabel, R. D., Taylor, J. F., \& Hillis, D. M. (2013). New World cattle show ancestry from multiple independent domestication events. Proceedings of the National Academy of Sciences, 110, E1398 - E1406.

Mendl, M., Brooks, J., Basse, C., Burman, O., Paul, E., Blackwell, E., \& Casey, R. (2010). Current Biology, 20, R839 R840.

Mendl, M., Burman, O., Parker, R. M. A., \& Paul, E. S. (2009). Cognitive bias as an indicator of animal emotion and welfare: Emerging evidence and underlying mechanisms. Applied Animal Behavior Science, 118, $161-181$.

Mendl, M., \& Paul, E. S. (2004). Consciousness, emotion and animal welfare: Insights from cognitive science. Animal Welfare, 13, S17 - S25.

Miller, K. A., Garner, J. P., \& Mench, J. A. (2006). Is fearfulness a trait that can be measured with behavioral tests? A validation of four fear tests for Japanese quail. Animal Behaviour, 71, 1323 - 1334.

Mintline, E. M., Stewart, M., Rogers, A. R., Cox, N. R., Verkerk, G. A., Stookey, J. M., Webster, J. R., \& Tucker, C. B., (2013). Play behavior as an indicator of animal welfare: Disbudding in dairy calves. Applied Animal Behaviour Science, $144,22-30$.

Miranda-de la Lama, G. C., Sepúlveda, W. S., Montaldo, H. H., María, G. A., \& Galindo, F. (2011). Social strategies associated with identity profiles in dairy goats. Applied Animal Behaviour Science, 134, 48 - 55.

Mittelbach, G. G., Ballew, N. G., \& Kjelvik, M. K. (2014). Fish behavioral types and their ecological consequences. Canadian Journal of Fisheries and Aquatic Sciences, 71, 927 - 944.

Mohr, E., Langbein, J., \& Nürnberg, G. (2002). Heart rate variability: A noninvasive approach to measure stress in calves and cows. Physiology \& Behavior, 75, $251-259$.

Molnár, C., Pongrácz, P., Faragó, T., Dóka, A., \& Miklósi, A. (2009). Dogs discriminate between barks: The effects of context and identity of the caller. Behavioural Processes, 82, $198-201$.

Moran, J. (1993). Calf rearing: A guide to rearing calves in Australia. Kyabram, Australia: Victorian Department of Agriculture.

Moran, J., \& Doyle, R. (2015) Cow talk: Understanding dairy cow behaviour to improve their welfare on Asian farms. Clayton South Victoria, Australia: CSIRO Publishing.

Mounier, L., Veissier, I., Andanson, S., Delval, E., \& Boissy, A. (2006). Mixing at the beginning of fattening moderates social buffering in beef bulls. Applied Animal Behaviour Science, 96, 185 - 200.

Müller, R., \& Schrader, L. (2005). Behavioural consistency during social separation and personality in dairy cows. Behaviour, 1420, $1289-1306$. 
Müller, R., \& von Keyserlingk, M. A. (2006). Consistency of flight speed and its correlation to productivity and to personality in Bos taurus beef cattle. Applied Animal Behaviour Science, 99, 193 - 204.

Munksgaard, L., de Passillé, A. M., Rushen, J., Thodber, K., \& Jensen, M. B. (1997). Discrimination of people by dairy cows based on handling. Journal of Dairy Science, 80, $1106-1112$.

Neave, H. W., Daros, R. R., Costa, J. H. C., von Keyserlingk, M. A. G., \& Weary, D. M. (2013). Pain and pessimism: Dairy calves exhibit negative judgement bias following hot-iron disbudding. PLoS One, 8, e880556.

Nicol, C. (2006). How animals learn from each other. Applied Animal Behaviour Science, 100, 58 - 63.

O'Connell-Rodwell, C. E., Wood, J. D., Kinzley, C., Rodwell, T. C., Alarcon, C., Wasser, S. K., \& Sapolsky, R. (2011). Male African elephants (Loxodonta africana) queue when the stakes are high. Ethology Ecology \& Evolution, 23, 388 397.

Ohl, F., Arndt, S., \& van der Staay, F. J. (2008). Pathological anxiety in animals. Veterinary Journal, 175, 18 - 26.

Olmos, G., \& Turner, S. P. (2008). The relationships between temperament during routine handling tasks, weight gain and facial hair whorl position in frequently handled beef cattle. Applied Animal Behaviour Science, 115, 25 - 36.

Ottoni, E. B., \& Mannu, M. (2001). Semifree-ranging tufted capuchins (Cebus apella) spontaneously use tools to crack open nuts. International Journal of Primatology, 22, $347-358$.

Palagi, E., Norscia, I., \& Demuru, E. (2014). Yawn contagion in humans and bonobos: Emotional affinity matters more than species. PeerJ2, e519.

Panksepp, J. (2004). Affective neuroscience: The foundations of human and animal emotions. New York, NY: Oxford University Press.

Paul, E. S., Harding, E. J., \& Mendl, M. (2005). Measuring emotional processes in animals: The utility of a cognitive approach. Neuroscience and Bio-Behavioral Reviews, 29, $469-491$.

Pérez-Torres, L., Orihuela, A., Corro, M., Rubio, I., Cohen, A., \& Galina, C. S. (2014). Maternal productive behavior of zebu type cattle (Bos indicus) and its association with temperament. Journal of Animal Science, 92, $4694-4700$.

Petherick, J. C., Doogan, V. J., Holroyd, R. G., Olsson, P., \& Venus, B. K. (2009). Quality of handling and holding yard environment, and beef cattle temperament: 1. Relationships with flight speed and fear of humans. Applied Animal Behaviour Science, 120, $18-27$.

Phillips, C. (2002). Cattle behavior and welfare. Oxford, UK: Blackwell Publishing.

Piller, C. A., Stookey, J. M., \& Watts, J. M. (1999). Effects of mirror-image exposure on heart rate and movement of isolated heifers. Applied Animal Behaviour Science, 63, 93 - 102.

Pomerantz, O., Terkel, J., Suomi, S. J., \& Paukner, A. (2012). Stereotypic head twirls, but not pacing, are related to a "pessimistic"-like judgement bias among captive tufted capuchins (Cebus apella). Animal Cognition, 15, 689 - 698.

Proctor, H. S., \& Carder, G. (2014). Can ear postures reliably measure the positive emotional state of cows? Applied Animal Behaviour Science, 161, 20-27.

Proctor, H. S., \& Carder, G. (2015a). Nasal temperatures in dairy cows are influenced by positive emotional state. Physiology \& Behavior, $138,340-344$.

Proctor, H. S., \& Carder, G. (2015b). Measuring positive emotions in cows: Do visible eye whites tell us anything? Physiology \& Behavior, 147, $1-6$.

Proudfoot, K. L., Weary, D. M., \& von Keyserlingk, M. A. (2012). Linking the social environment to illness in farm animals. Applied Animal Behaviour Science, 138, $203-215$.

Puppe, B., Langbein, J., Bauer, J., \& Hoy, S. (2008). A comparative view on social hierarchy formation at different stages of pig production using sociometric measures. Livestock Science, 113, $155-162$.

Range, F., Aust, U., Steurer, M., \& Huber, L. (2008). Visual categorization of domestic stimuli by domestic dogs. Animal Cognition, 11, $338-347$.

Rault, J-L. (2012). Friends with benefits: Social support and its relevance for farm animal welfare. Applied Animal Behaviour Science, 136, $1-14$.

Reale, D., Reader, S. M., Sol, D., \& McDougall, P. T., \& Dingemanse, N. J. (2007). Integrating animal temperament within ecology and evolution. Biological Reviews of the Cambridge Philosophical Society, 82, $291-318$.

Rehkämper, G., \& Görlach, A. (1997). Visual discrimination in adult dairy bulls. Journal of Dairy Science, 80, 1613 - 1621.

Reimert, I., Bolhuis, J. E., Kemp, B., \& Rodenberg, T. (2013). Indicators of positive and negative emotions and emotional contagion in pigs. Physiology and Behavior, 109, $42-50$.

Reimert, I., Bolhuis, J. E., Kemp, B., \& Rodenburg, T. B. (2014). Emotions on the loose: Emotional contagion and the role of oxytocin in pigs. Animal Cognition, 18, $517-532$.

Reinhardt, V., Mutiso, F. M., \& Reinhardt, A. (1978). Social behavior and social relationships between female and male prepubertal bovine calves (Bos indicus). Applied Animal Ethology, 4, $43-54$.

Rodenburg, T. B., Bolhuis, J. E., Reimert, I., \& Kemp, B. (2014). Social support in pigs with different coping styles. Physiology and Behavior, 129, $221-229$. 
Romero, T., Ito, M., Saito, A., \& Hasegawa, T. (2014). Social modulation of contagious yawning in wolves. PLoS One, 9 , e105963.

Rubenstein, D. I., Sundaresan, S., Fischoff, I., \& Saltz, D. (2007). Social networks in wild asses: Comparing patterns and processes among populations. Erforscht Biology Research Mongolei, 10, 159 - 176.

Sandem, A. I., \& Braastad, B. O. (2005). Effects of cow-calf separation on visible eye white and behaviour in dairy cows. A brief report. Applied Animal Behaviour Science, 95, 233 - 239.

Sandem, A., Braastad, B. O., \& Bakken, M. (2006). Behaviour and percentage eye-white in cows waiting to be fed concentrate. A brief report. Applied Animal Behaviour Science, 97, 145 - 151.

Sandem, A. I., Braastad, B. O., \& Bøe, K. E. (2002). Eye white may indicate emotional state on a frustration-contentedness axis in dairy cows. Applied Animal Behaviour Science, 79, $1-10$.

Sandem, A. I., \& Janczak, A. (2006). The use of diazepam as a pharmacological validation of eye white as an indicator of emotional state in dairy cows. Applied Animal Behaviour Science, 96, 177 - 183.

Sato, S. (1994). Social licking pattern and its relationships to social dominance and live weight gain in weaned calves. Applied Animal Behaviour Science, 12, 25 - 32.

Sato, S., Woodgush, D. G. M., \& Wetherill, G. (1987). Observations on crèche behavior in suckler calves. Behavioural Processes, 15, $333-343$.

Schaeffer, R. G., \& Sikes, J. D. (1970). Discrimination learning in dairy calves. Journal of Dairy Science, 54, 893 - 896.

Schneider, R. L., Schiml, P. A., Deak, T., \& Hennessy, M. B. (2012). Persistent sensitization of depressive-like behavior and thermogenic response during maternal separation in pre- and post-weaning guinea pigs. Developmental Psychobiology, 54, $514-522$.

Schuett, W., Dall, S. R., \& Royle, N. J. (2011). Pairs of zebra finches with similar 'personalities' make better parents. Animal Behavior, 81, $609-618$.

Schwartzkopf-Genswein, K. S., Stookey, J. M., \& Welford, R. (1997). Behavior of cattle during hot-iron and freeze branding and the effects on subsequent handling ease. Journal of Animal Science, 75, 2064 - 2072.

Seyfarth, R., \& Cheney, D. (2015). How sociality shapes the brain, behaviour and cognition. Animal Behaviour, 103, 187 190.

Shettleworth, S. J. (2002). Spatial behavior, food storing, and the modular mind. In M. Bekoff, C. Allen, \& G. M. Burghardt (Eds.), The cognitive animal (pp. 123 - 128). Cambridge, MA: MIT Press.

Shettleworth, S. J. (2010). Cognition, evolution, and behavior. $2^{\text {nd }}$ ed. New York, NY: Oxford University Press.

Shin, D., Kang, H., \& Seo, S. (2017). Social relationships enhance the time spent eating and intake of a novel diet in pregnant Hanwoo (Bos taurus coreanae) heifers. PeerJ, 5, e3329

Sly, J., \& Bell, F. R. (1979). Experimental analysis of the seeking behaviour observed in ruminants when they are sodium deficient. Physiology and Behavior, 22, 499 - 505.

Sly, J., \& Bell, F. R. (1981). Effect of lithium intake on sodium and lithium appetite in sodium deficient cattle. Physiology and Behavior, 27, $147-152$.

Solano, J., Orihuela, A., Galina, C. S., \& Aguirre, V. (2007). A note on behavioral responses to brief cow-calf separation and reunion in cattle (Bos indicus). Journal of Veterinary Behavior: Clinical Applications and Research, 2, 10 - 14.

Stafford, K., \& Mellor, D. (2011). Addressing the pain associated with disbudding and dehorning in cattle. Applied Animal Behaviour Science, 135, 226 - 231.

Stěhulová, I., Špinka, M., Šárová, R., Máchová, L., Kněz, R., \& Firla, P. (2013). Maternal behaviour in beef cows is individually consistent and sensitive to cow body condition, calf sex and weight. Applied Animal Behaviour Science, 144, $89-97$.

Stewart, M., Shepherd, H., Webster, J., Waas, J., McLeay, L., \& Schutz, K. (2013). Effect of previous handling experiences on responses of dairy calves to routine husbandry procedures. Animal, 7, $828-833$.

Surbeck, M., Mundry, R., \& Hohmann, G. (2011). Mothers matter! Maternal support, dominance status and mating success in male bonobos (Pan paniscus). Proceedings of the Royal Society of London B: Biological Sciences, 278, $590-$ 598.

Svartberg, K., Tapper, I., Temrin, H., Radesäter, T., \& Thorman, S. (2005). Consistency of personality traits in dogs. Animal Behaviour, 69, $283-291$.

Tanida, H., \& Nagano, Y. (1998). The ability of miniature pigs to discriminate between a stranger and their familiar handler. Applied Animal Behaviour Science 56, 149 - 159.

Taylor, A. A., \& Davis, H. (1998). Individual humans as discriminative stimuli for cattle Bos taurus. Applied Animal Behavior Science, 58, $13-21$.

Thorsteinsson, E. B., James, J. E., \& Gregg, M. E. (1998). Effects of video-relayed social support on hemodynamic reactivity and salivary cortisol during laboratory-based behavioral challenge. Health Psychology, 17, 436 - 444. 
Toms, C. N., Echevarria, D. J., \& Jouandot, D. J. (2010). A methodological review of personality-related studies in fish: Focus on the shy-bold axis of behavior. International Journal of Comparative Psychology, 23, 1 - 25.

Trezza, V., Baarendse, P. J. J., \& Vanderschuren, L. J. M. J. (2010). The pleasures of play: Pharmacological insights into social reward mechanisms. Trends in Pharmacological Science, 31, 463- 469.

Val-Laillet, D., Guesdon, V., von Keyserlingk, M. A. G., de Passillé, A. M., \& Rushen, J. (2009). Allogrooming in cattle: Relationships between social preferences, feeding displacements and social dominance. Applied Animal Behaviour Science, 116, $141-149$.

Van Reenan, C. G., Van der Werf, J. T. N., Bruckmaier, R. M., Hopster, H., Engel, B., Noordhuisen, J. P. T. M., \& Blokhuis, H. J. (2002). Individual differences in behavioral and physiological responsiveness of primiparous dairy cows to machine milkings. Journal of Dairy Science, 85, $2551-2561$.

Van Reenen, C. G., Van der Werf, J. T., O'Connell, N. E., Heutinck, L. F., Spoolder, H. A., Jones, R. B., Koolhaas, J. M., Blokhuis, H. J., O'Connell, N. E., \& Lantbruksuniversitet, S. (2013). Behavioural and physiological responses of heifer calves to acute stressors: Long-term consistency and relationship with adult reactivity to milking. Applied Animal Behaviour Science, 147, 55 - 68.

Van Reenen, C. G., Jensen, M. B., Bokkers, E. A. M., Schmitt, O., \& Webb, L. E. (2015). Does temperament affect learning in calves? Applied Animal Behaviour Science, 165, 33 - 39.

Vieira, A. D. P., de Passillé, A. M., \& Weary, D. M. (2012). Effects of the early social environment on behavioral responses of dairy calves to novel events. Journal of Dairy Science, 95, $5149-5155$.

Veissier, I., Gesmier, V., Le Neindre, P., Gautier, J. Y., \& Bertrand, G. (1994). The effects of rearing in individual crates on subsequent social behaviour of veal calves. Applied Animal Behaviour Science, 41, $199-210$.

Vonk, J., Weiss, A., \& Kuczaj, S. (Eds.) (2017). Personality in nonhuman animals. New York, NY: Springer.

von Keyserlingk, M. A., \& Weary, D. M. (2007). Maternal behavior in cattle. Hormones and Behavior, 52, 106 - 113.

Wagner, K., Barth, K., Hillmann, E., Palme, R., Futschik, A., \& Waiblinger, S. (2013). Mother rearing of dairy calves: Reactions to isolation and to confrontation with an unfamiliar conspecific in a new environment. Applied Animal Behaviour Science, 147, 43 - 54.

Wagner, K., Seitner, D., Barth, K., Palme, R., Futschik, A., \& Waiblinger, S. (2015). Effects of mother versus artificial rearing during the first 12 weeks of life on challenge responses of dairy cows. Applied Animal Behaviour Science, $164,1-11$.

Walker, J., Arney, D., Waran, N., Handel, I., \& Phillips, C. (2015). The effect of conspecific removal on behavioral and physiological responses of dairy cattle. Journal of Dairy Science, 98, 8610 - 8622.

Weary, D. M., \& Chua, B. (2000). Effects of early separation on the dairy cow and calf: 1. Separation at 6 h, 1 day and 4 days after birth. Applied Animal Behaviour Science, 69, 177 - 188.

Weary, D. M., Niel, L., Flower, F. C., \& Fraser, D. (2006). Identifying and preventing pain in animals. Applied Animal Behavior Science, 100, $64-76$.

Weaver, S. (2012). The backyard cow: An introductory guide to keeping a productive family cow. North Adams, Massachusetts: Storey Publishing.

Webb, L., Engel, B., Berends, H., van Reenen, C., Gerrits, W., de Boer, I., \& Bokkers, E. (2014). What do calves choose to eat and how do preferences affect behaviour? Applied Animal Behaviour Science, 161, 7 - 19.

Whiten, A. (1998). Imitation of the sequential structure of actions by chimpanzees (Pan troglodytes). Journal of Comparative Psychology, 112, $270-281$.

Yamamoto, S., Humley, T., \& Tanaka, M. (2013). Basis for cumulative cultural evolution in chimpanzees: Social learning of a more efficient tool-use technique. PLOS One, 8, e55768.

Zentall, T. R. (2012). Perspectives on observational learning in animals. Journal of Comparative Psychology, 126, 114.

Zentall, T., \& Wasserman, E. (Eds.) (2006). Comparative cognition: Experimental explorations of animal intelligence. New York, NY: Oxford University Press.

Zylinski, S. (2015). Fun and play in invertebrates. Current Biology, 25, R10 - R12. 